\title{
Mandibulate convergence in an armoured Cambrian stem chelicerate
}

\author{
Cédric Aria ${ }^{1,4^{*}}$ and Jean-Bernard Caron ${ }^{1,2,3}$
}

\begin{abstract}
Background: Chelicerata represents a vast clade of mostly predatory arthropods united by a distinctive body plan throughout the Phanerozoic. Their origins, however, with respect to both their ancestral morphological features and their related ecologies, are still poorly understood. In particular, it remains unclear whether their major diagnostic characters were acquired early on, and their anatomical organization rapidly constrained, or if they emerged from a stem lineage encompassing an array of structural variations, based on a more labile "panchelicerate" body plan.

Results: In this study, we reinvestigated the problematic middle Cambrian arthropod Habelia optata Walcott from the Burgess Shale, and found that it was a close relative of Sanctacaris uncata Briggs and Collins (in Habeliida, ord. nov.), both retrieved in our Bayesian phylogeny as stem chelicerates. Habelia possesses an exoskeleton covered in numerous spines and a bipartite telson as long as the rest of the body. Segments are arranged into three tagmata. The prosoma includes a reduced appendage possibly precursor to the chelicera, raptorial endopods connected to five pairs of outstandingly large and overlapping gnathobasic basipods, antennule-like exopods seemingly dissociated from the main limb axis, and, posteriorly, a pair of appendages morphologically similar to thoracic ones. While the head configuration of habeliidans anchors a seven-segmented prosoma as the chelicerate ground pattern, the peculiar size and arrangement of gnathobases and the presence of sensory/tactile appendages also point to an early convergence with the masticatory head of mandibulates.
\end{abstract}

Conclusions: Although habeliidans illustrate the early appearance of some diagnostic chelicerate features in the evolution of euarthropods, the unique convergence of their cephalons with mandibulate anatomies suggests that these traits retained an unusual variability in these taxa. The common involvement of strong gnathal appendages across non-megacheiran Cambrian taxa also illustrates that the specialization of the head as the dedicated foodprocessing tagma was critical to the emergence of both lineages of extant euarthropods-Chelicerata and Mandibulata - and implies that this diversification was facilitated by the expansion of durophagous niches.

Keywords: Arthropoda, Chelicerata, Convergence, Macroevolution, Cambrian, Burgess Shale

\section{Background}

The early evolution of arthropods has long been emblematic of the "Cambrian Explosion" [1, 2], and has grown through the past decades into a remarkable variety of "stem" taxa [3-9], attracting emphasis on phylogenetic similarities (homologies) and exceptional divergences between morphologies. This is because morphological similarities of a common descent allow for the placement

\footnotetext{
* Correspondence: cedric.aria@protonmail.com

'Department of Ecology and Evolutionary Biology, University of Toronto, Toronto, ON M5S3B2, Canada

${ }^{4}$ Present address: State Key Laboratory of Palaeobiology and Stratigraphy, Nanjing Institute of Geology and Palaeontology, Chinese Academy of Sciences, Nanjing 210008, China

Full list of author information is available at the end of the article
}

of "weird wonders" on a phylogenetic tree $[3,5,10,11]$, while the emphasis on divergences promotes the idea of unusual morphological variability in the early evolution of clades [2]. Homoplasies, by contrast, have received less attention in that context [12].

In spite of being discarded when reconstructing phylogenetic relationships, phenotypic convergence remains an informative (palaeo)biological observation, as it can also illustrate the formidable morphological variability deployed within or across body plans in response to similar selective pressures [13-16]. In the Cambrian, remarkable cases of convergence have been documented in which body plans or appendages are reminiscent of derived taxa due to the early occupation of the same 
niches $[17,18]$. At the same time, convergences are well known to outline some of the structural constraints shared by different groups of species. A prominent case of convergence involving all types of Palaeozoic and extant euarthropods is the distal differentiation of appendages into pincers $[9,12]$.

Broad morpho-functional convergences may be less expected between early-diverging lineages, as we would think that recently selected traits would provide greater fitness for the exploration of new niches, and that disruptive selection would impact the phenotype at large-even when considering the role of mosaic evolution. Thus, for instance, early representatives of the two extant euarthropod clades, Chelicerata and Mandibulata, would have been morphologically diverging rather than converging, developing different morpho-functional adaptations and "maturing" their respective body plans to form the basis of their great diversification during the Phanerozoic.

However, little is still known about the origin per se of extant lineages and about the significance of Cambrian high evolutionary rates [19] and, questionably [20, 21], exceptional morphological variability $[2,22,23]$ on their stem taxa. We recently proposed a scenario for the early radiation of Mandibulata based on a reevaluation of bivalved arthropod anatomy [9], which represents a new avenue of research based on adult macrofossils to explore these questions. The origin of chelicerates, on the other hand, has been the subject of some more active debate in recent years [24-28]. Based on the topology and structural similarity between chelicerae and "great appendages," some authors [24, 25, 29] have proposed a phylogenetic continuity between these frontal limbs. Although this does not imply that megacheirans (bearing the great appendages) and chelicerates necessarily form a clade, this has been hypothesized as such [12, 28, 30, 31], assuming that the chelate nature of these appendages constitutes an apomorphy for these taxa, contrasting with the antennular anteriormost appendages present in other euarthropods.

Although the grouping of megacheirans with chelicerates has been retrieved phylogenetically [6], it has been shown to be a possible methodological (polarization) bias associated with the retrieval of Arachnomorpha under parsimony [27]. More recent analyses have found megacheirans (or, at least, cheiromorphs) to be more basal, possibly forming a sister group to artiopodans and extant clades $[8,9]$. Apart from considering great appendages to be the direct precursors of the chelicerae, there does not seem indeed to be any unambiguous character supporting the placement of megacheirans on the chelicerate lineage.

Instead of megacheirans, the groundplan of chelicerates could be represented by the Burgess Shale species
Sanctacaris [26], as originally proposed by Briggs and Collins [32]. Sanctacaris has been shown so far to display a five- or six-segmented cephalon, a condition closer to the euchelicerate condition (six-segmented) than the four-segmented head of megacheirans. However-and there lies the conundrum-, in addition to several uncertainties regarding its head configuration, such as the forward attachment of its raptorial limbs in a "bundle," Sanctacaris lacks a clear indication of a chelate frontalmost appendage comparable to the chelicera. A series of very recent studies have documented other forms with likely affinities to Sanctacaris from the Spence and Wheeler Shales in Utah [33, 34] and the Emu Bay Shale in Australia [35], but this particular uncertainty still remains.

It may also be considered that both megacheirans (or at least some of them) and Sanctacaris-like morphotypes are part of the chelicerate lineage, with Sanctacaris bearing, for instance, very reduced great appendages. This idea would conflict with a scenario in which antennulebearing artiopodans (and in particular xenopodans, i.e., Sidneyia and Emeraldella) would constitute the basalmost part of this lineage, based mainly on a comparison between their exopod morphology and the gill opercula of euchelicerates [26]. Such comparison remains tentative, however, and further assessment of possible chelicerate affinities are notably hampered by a limited knowledge of the xenopodan head anatomy.

In this study, we thoroughly reinvestigated the Burgess Shale euarthropod Habelia Walcott, 1912 based on Walcott's original material and new specimens discovered by the Royal Ontario Museum. Habelia optata was initially regarded by Walcott as an "aglaspidid merostome," which would hint at a chelicerate affinity [36], but this statement lacked much justification [37]. Simonetta [38] and Simonetta and Delle Cave [39] followed this view based mostly on overall aspect, while preferring to compare $H$. brevicauda, the new morphotype erected by Simonetta, to Leanchoilia [39] - a megacheiran. Importantly, early authors [37-41] recognized the presence of at least five pairs of head appendages, a condition that could have later related this animal to Sanctacaris-even if an interpretation of strictly five pairs and some other morphological details led to comparisons with crustaceans instead [40,42]. In his revision of the genus, however, Whittington [43] rejected previous interpretations of a cephalon with five head appendages or more, leaving Habelia as a problematicum.

Herafter, we reevaluate the significance of Habelia for the early evolution of chelicerates, as well as for the understanding of morphological convergence in the ecological context of the radiation of Cambrian euarthropods. 


\section{Methods}

\section{Fossil material and observation}

Most specimens were collected in situ from the Greater Phyllopod Bed within the Burgess Shale Walcott Quarry, in Yoho National Park, British Columbia. Two additional specimens come from other Burgess Shale localities (see Additional file 1 for a detailed list of studied specimens). 41 specimens were studied in total, including 14 from the National Museum of Natural History, Washington D.C. (USNM), and 27 new specimens from the Royal Ontario Museum Invertebrate Palaeontology collections in Toronto (ROMIP). Methodology for observation followed our previous studies on Burgess Shale arthropods [9, 27, 44]. Selected specimens were mechanically prepared to remove matrix covering anatomical features. All material was observed under a stereomicroscope equipped with polarizing filters, and photographed both dry and wet under natural and cross-polarized lighting, occasionally using ammonium chloride sublimate to highlight three-dimensional details.

\section{Phylogenetic analyses}

We used a Bayesian technique of tree search on a revised version of a previously published dataset [9], now comprising 77 taxa and 215 characters, all unweighted and unordered (see Additional file 2, ref. [9] for overall character descriptions and Additional file 1 for improvements), and with inapplicable entries treated as uncertainties. The topology was generated using MrBayes v.3.2.6 [45], with parameter settings following the Mkv method [46]. As per MrBayes' restrictions, Priapulida was used as the single outgroup (following refs. [47, 48]), but was subsequently retrieved in a polytomy with Nematoda. Trees were produced during four runs of 5,000,000 generations with four parallel chains, a tree sampled every 1000 generation and burn-in of $20 \%$. Among-character rates were set to remain equal. A Bayesian treatment of our data was chosen to explore an alternative methodology to parsimony, which is particularly sensitive to the suboptimal treatment of inapplicable states [27]. Bayesian analyses have also been shown to provide more accurate results than parsimony, albeit with a possible loss of precision $[49,50]$. In order to account for the morphological and molecular signal that can only be coded among extant taxa, we chose to apply a backbone constraint on our dataset, based on the topology of Regier et al. [51]. As in ref. [9], we preferred this method over the direct implementation of numerous extant-only characters to avoid overburdening the dataset with question marks, which causes instability and a lack of resolution in (relatively) small datasets [52, 53]. Finding inconsistencies of placement with different codings of the head anatomy, pycnogonids were removed from the analysis presented here (see Phylogenetic results).

\section{Abbreviations and terminology}

Abbreviations used in figures: ag, anterior gnathobase; am, arthrodial membrane; an, anus; ap, anal pouch; att, endopod attachment on gnathobase; bas, basipod(s); ce, cephalic endopod(s); cen, cephalic endopod $n$; cel, left cephalic exopods; cpl, cephalic pleura; cx, cephalic exo$\operatorname{pod}(\mathrm{s})$; $\operatorname{cx} n$, cephalic exopod $n$; db, distal brush; dpex, distal part of exopod; ds, dorsal spine; dtp; distal telson piece; e, eye; en, endopod $n$; en, endopod; ex, exopod; das, dark stain; g, gnathobase(s); gnl, left gnathobase $n$; gnr, right gnathobase $n$; hyp, hypostome; ia, intermediary appendage; it, intestine; jt, joint; la, labrum; $m$, mouth; nv?, nerve?; oe, oesophagus; $n n$, podomere $n$; pex, posterior exopod(s); pex $n$, posterior exopod $n$; ppex, proximal part of exopod; ptp, proximal telson piece; rap, reduced anterior appendage(s); st, stomach; $\mathrm{t} n$, thoracic appendage $n$; te, thoracic endopod(s); tel., telson, te $n$, thoracic endopod $n$; th, telson head; tpl, trunk pleura(e). Hereafter, we call "gnathobasic appendage" an appendage whose basipod is gnathobasic, that is, differentiated into a masticatory structure (more strongly sclerotized, often bearing ornaments such as setae and teeth).

\section{Results}

\section{Systematic palaeontology}

Superphylum Panarthropoda Nielsen, 1995.

Phylum Euarthropoda Lankester, 1904.

Clade Arachnomorpha Heider, 1913 (= Arachnata Lauterbach, 1973).

Diagnosis (emended from Størmer, 1944). Euarthropods with the following characters: Cephalic shield encompassing at least four pairs of appendages with well-developed endopods; originally, presence along body of at least one pair of appendages with basipod differentiated into a well-sclerotized gnathal sclerite bearing setae or teeth ("gnathobasic appendage"); third gnathobasic cephalic appendage also part of groundplan; post-cephalic endopods terminating in a trident of claws with various arrangements.

\section{Order Habeliida, ord. nov. Aria and Caron}

Type family. Habeliidae Simonetta and Delle Cave, 1975.

Other included taxa. Sanctacarididae Legg and Pates, 2016.

Diagnosis. Arachnomorph arthropods with the following characters: Cephalic shield with sub-triangular, subhorizontal pleural expansions and with antero-lateral notches accommodating pair of lateral compound eyes with no peduncle; cephalic shield with large mesiodorsal bulge accommodating stomach; five pairs of anterior, slender and segmented antennule-like exopods likely inserted below the eyes and dorsally to other head appendages; on ventral side of head, reduced pair of 
appendages inserted anteriormost (presumed in Sanctacarididae), followed by five pairs of appendages composed of gnathobasic basipods increasing in size posteriad and bearing seven-segmented spinose/setose enditic endopods projecting anteriad; trunk bearing paddle-like exopods fringed with thin lamellae.

Remarks. We maintain the family Sanctacarididae erected by Legg and Pates [33], since 10 trunk segments and a spatulate telson remain diagnostic of Sanctacaris uncata, Utahcaris orion [33] and Wisangocaris barbarahardyae [35]. The affinity of Messorocaris magna [34] is less clear, but the peculiar shape of its trunk pleurae may place it in its own family.

Habelia had previously been assigned to the orders Aglaspina by Walcott and Emeraldellia by Størmer [36]. Given the lack of cladistic support for these taxa, which would be para- or polyphyletically nested within Arachnomorpha, the lack of redescription for Molaria, and the fact that their diagnoses should be extensively revised in light of the new data gathered on aglaspidids and Emeraldella, we have not reused Aglaspina or Emeraldellia herein.

Family Habeliidae Simonetta and Delle Cave, 1975.

Type genus. Habelia Walcott, 1912.

Diagnosis. Habeliidan euarthropods with the following characters: Body elongate, 19-segmented, divided into three distinct tagmata: cephalon (or "prosoma") of seven segments (or eight somites) and trunk (12 segments) composed of a five-segmented thorax (or "mesosoma") and eight-segmented post-thorax (or "metasoma"); trunk tagmatization based on discrete limb differentiation between thorax and post-thorax; posteriormost cephalic appendage (7th) similar to thoracic appendages, all characterized by a cheiromorph morphology: large undifferentiated basipods, well-developed seven-segmented endopods without endites, and paddle-like exopods fringed with oblanceolate lamellae; telson elongate.

Remarks. We hereby establish a diagnosis for the family Habeliidae, as the original publication of the taxon was not associated with one [39]; we also formalize diagnoses and descriptions for Habelia optata hereafter. The genus Thelxiope was also included in Habeliidae by Simonetta and Delle Cave; however, the presence of eight post-cephalic tergites and a pygidium would rather seem to indicate a relationship with Mollisonia $[54,55]$. Thelxiope is therefore removed from Habeliidae.

Genus Habelia Walcott, 1912.

(Figures 1, 2, 3, 4; Additional file 3, Additional file 4, Additional file 5, Additional file 6, Additional file 7 and Additional file 8)

Type species. Habelia optata Walcott, 1912.

Diagnosis. Habeliid arthropod with the following characters: Post-ocular lateral and postero-lateral cephalic margins as well as pleural margins of trunk segments adorned with triangular spines; cuticular surface of cephalon and posterior portion of trunk segments richly adorned with small blunt spines/tubercles; cephalic gnathobases with elongate proximal "arm"; gnathobasic teeth differentiated antero-posteriorly (slender and long to short and stout); cephalic endopods with setal brush on podomeres 5 and 6; five-segmented thorax bearing strong biramous appendages with robust, clawed endopods and long basipods; very long (subequal to slightly greater than head and trunk length) bipartite telson, with a long, dentate proximal portion adorned with lateral spines, and a short distal portion about $1 / 3$ rd as long as proximal portion.

Description. Habitus. Body 8.5 to $34 \mathrm{~mm}$ (without telson), elongate, 19-segmented and tagmatized (Fig. 1): cephalon (seven segments with tergites fused in a single shield) (Figs. 1, 2a-g), trunk (12 segments) (Fig. 1), tailpiece (bipartite) (Fig. 1); trunk subdivided into tagma II/"mesosoma" (five anteriormost segments) and tagma III/"metasoma" (Fig. 1); "mesosoma" bearing robust walking legs (Fig. 1); tailpiece a very long (ca. length of cephalon and trunk) and slender spiniform telson with articulated terminal piece (Fig. 1f, g).

Cephalon ("prosoma"). About 30\% of trunk length; length about $80 \%$ of width (Fig. 1). Composed of a central, bulging area, housing the stomach, and of lateral pleural expansions of the tergal shield, sub-aligned with the frontal plane (Fig. $2 \mathrm{~g}$ and Additional file 3, Additional file 4, Additional file 5, Additional file 6, Additional file 7). Broad and sub-triangular in dorsal view, with antero-medial margin separated from lateral (pleural) margins by strong ocular notches (Figs. 1b, 2a and Additional file 3, Additional file 4, Additional file 5). In lateral view, dorsal section of the cephalic shield high and sub-convex with relatively longer anterior face; ocular notch strongly impressed at the anterior junction between dorsal and postero-lateral sections of head shield; cephalic pleurae usually not visible in lateral view, due to their sub-horizontal position (Figs. 1, 2a, b). Pleural margins of the cephalic shield adorned with short, triangular spines (Fig. 2g and Additional file 6, Additional file 7); cephalic shield adorned on its entire surface with numerous, scattered short and blunt spines (Fig. 1b, h).

Eyes. Presence of a pair of spherical lateral eyes, presumably compound, inserted at the anterior notches between dorso-medial head bulge and lateral pleurae; approximately the size of the notches, i.e. $14 \%$ of head length in diameter; no trace of peduncle (Figs. 1a-d, 2a, g).

Hypostome-labrum complex. The anteriormost margin of the body bears medially a structural complex composed of dorsal and ventral elements, homologized here with labrum and hypostome.

Labrum. Anteriormost is a bulging body protrusion with length ca. $13 \%$ of head length, with rounded 


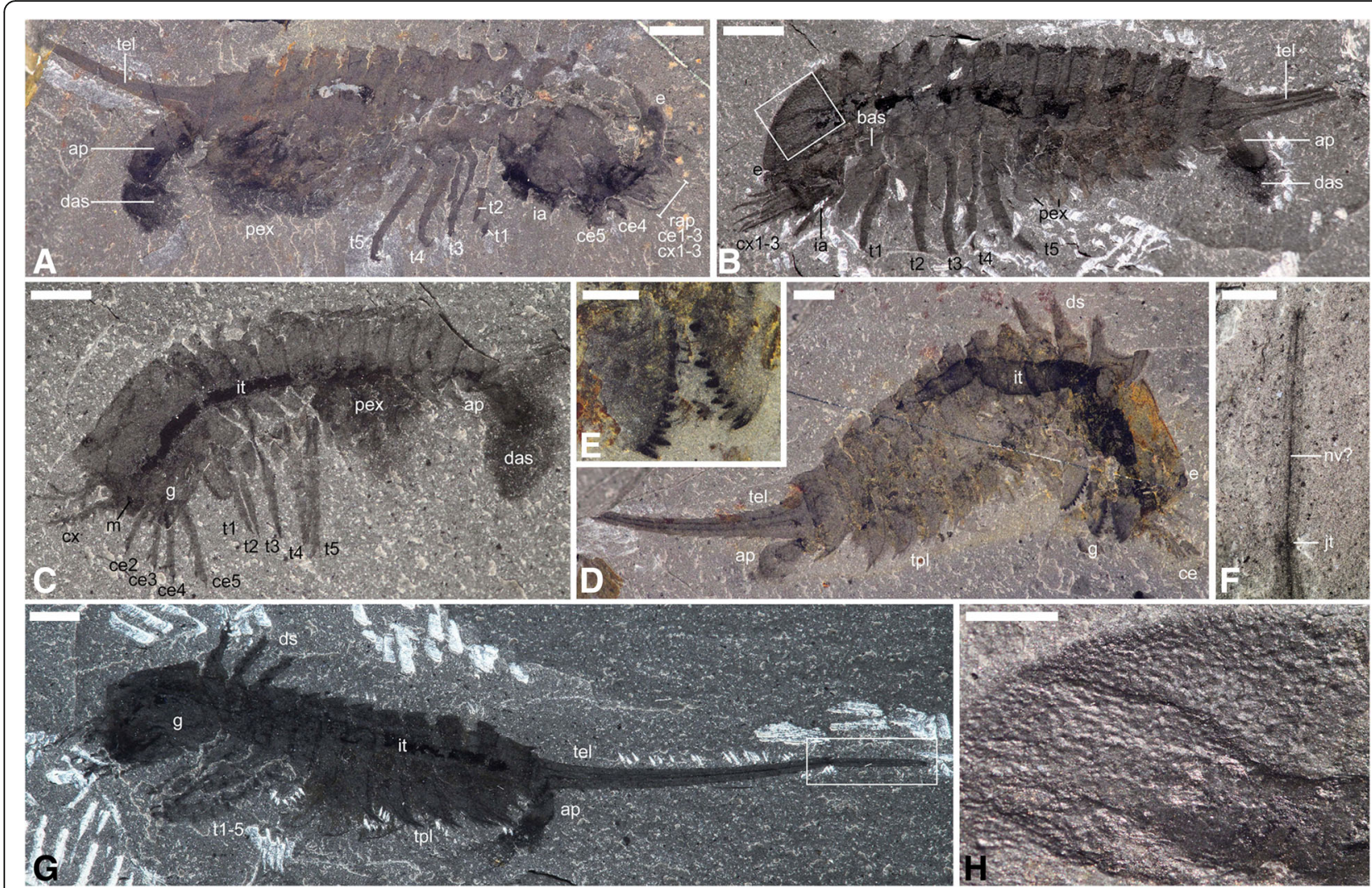

Fig. 1 General anatomy of Habelia optata, morphs A (d-g) and B (a-c, h). a ROMIP 64357. b USNM 139209 (inset is (h)). c ROMIP 64358. d ROMIP 64359. e Close-up of the mandibles on the counterpart of (d) (wet specimen). $\mathbf{f}$ Close-up of the distal telson piece in (g) (wet specimen). $\mathbf{g}$ Holotype USNM 57693 (inset is (f)). $\mathbf{h}$ Close-up on cephalic ornamentation akin to trilobite prosopon in (b). All pictures taken under cross-polarized light. For abbreviations, see Methods. Scale bars: (a), 4 mm; (b), 3 mm; (c, d, g), 2 mm; (e, f, h), 1 mm

anterior margin slightly extending beyond head shield in dorsal view, and interpreted as a labrum (Fig. 2g, i).

Hypostome. In ventral view, a sclerite with possible midline separation beneath the frontal protrusion (labrum) is interpreted as a hypostome (Fig. $2 \mathrm{~g}$ ).

Mouth. Mouth opening located very anteriorly, above first pair of gnathobases, and opening ventrally (Figs. 1c, 2d).

Alimentary tract. Gut differentiated into foregut, stomach and intestine; foregut directed dorsally ("oe" in Fig. 2d), gently curving posteriorly towards a large stomach; stomach much wider than deep, occupying most of head space and partly housed within a dorsal bulge of the cephalon (Fig. 1d); stomach constricted at the posterior margin of cephalon to form the intestine, ca. 1/4 of body width, tapering to trunk segment 5 , and finally reduced to a much smaller (ca. 1/3 of anterior diameter) duct in trunk segment 6 (Fig. 1c-g); anus opening posteriorly in anal pouch (Fig. 1a-d, g; see "tailpiece" section below).

Cephalic appendages. Post-ocular appendicular head composed of a pair of reduced frontal-most appendages, a series of branched antennule-like appendages and a series of five large, elongate, toothed, forward-oriented gnathobases bearing seven-segmented elongate spinose legs (Figs. 1, 2); an additional pair of appendages, with broad, rounded exopods and well-developed endopods, is located between the cephalon and trunk, but likely belongs to the cephalic tagma in the absence of dedicated trunk tergite (Figs. 1b, 2a, g and Additional file 5, Additional file 6).

Frontal-most appendage pair. Flexible (articulated?) and very short (about half the length of the following first gnathobasic appendage's endopod) (Fig. 2i-m); termination unclear, claw possibly present (Fig. 2i).

Post-frontal series of appendages. Five pairs of hypertrophied gnathobases occupy most of ventral space under head shield (Figs. 1, 2); gnathobases with toothed, straight masticatory margin parallel to ventral margin concentrated ca. within the anterior first $40 \%$ of head length (in short succession), so that the portion between masticatory margin and attachment ("arm") is increasingly elongated in posterior gnathobases-reaching up to ca. $50 \%$ of head shield length for appendage 5 (Figs. 1c, 


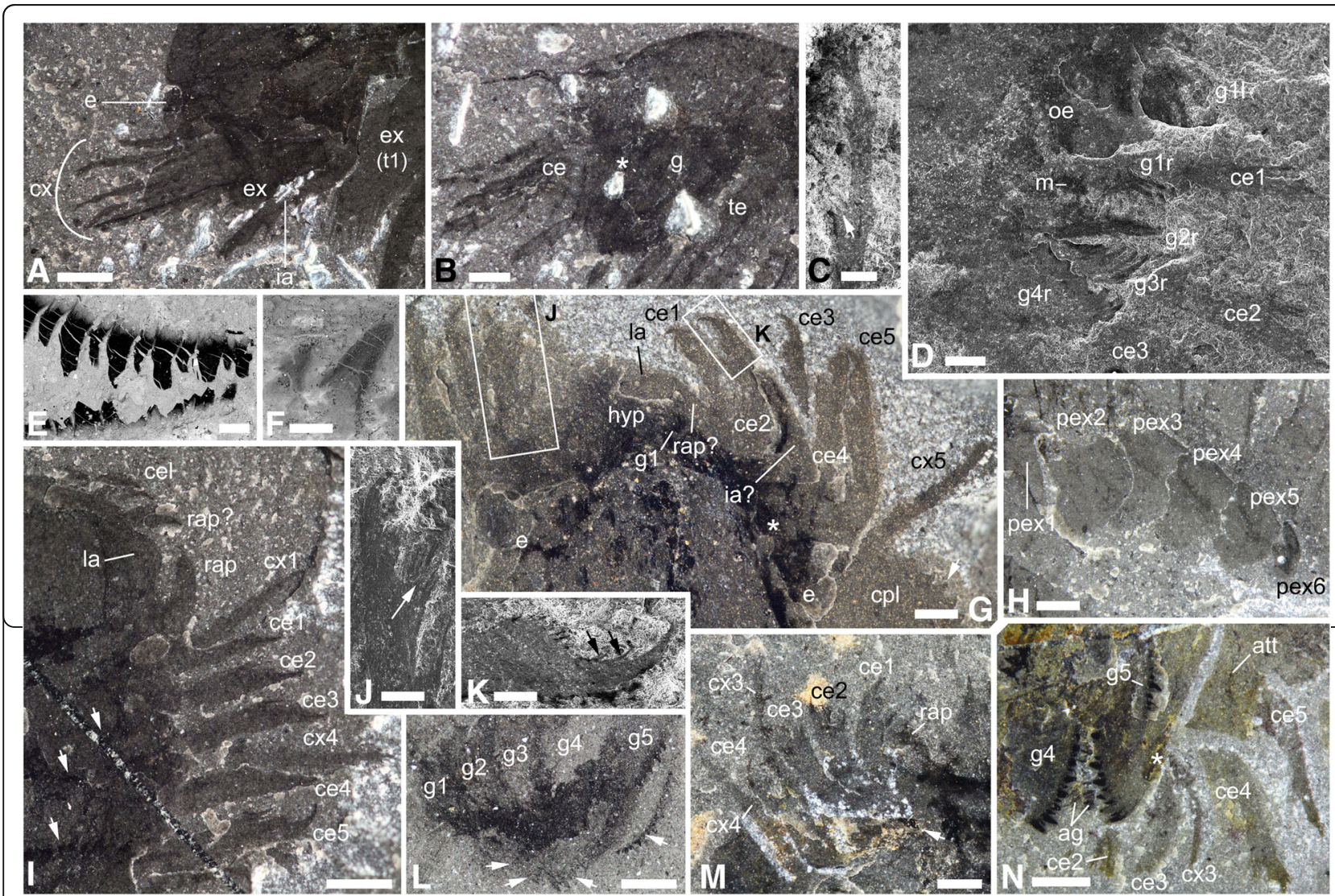

Fig. 2 Anatomical and morphological details of Habelia optata, morphs A (b, d, f, n) and B (a, e, g, i, I, m). a USNM 139209, close-up of anterior cephalic area, showing intermediary appendage. b USNM 268931, cephalon, showing superimposed insertion of endopods on gnathobases; star points to insertion of anterior endopods. c ROMIP 64357, close-up of fourth cephalic exopodial branch, distal portion showing slender podomeres; arrow points to trident of setae at podomere junction. d ROMIP 64358, close-up of anteriormost region, showing mouth opening and first anterior pairs of gnathobases. e ROMIP 64360, close-up of teeth on masticatory margin of gnathobase; note heavy concentration of carbon in teeth. $\mathbf{f}$ Close-up of teeth on masticatory margin of posterior gnathobase on same specimen as in D, showing stronger carbon content in dental edge. $\mathbf{g}$ ROMIP 64364, specimen preserved in ventral aspect, close-up of anterior region showing labrum, eyes and appendages; star marks attachment of fifth spinose endopod; arrow points at ornamental spine of cephalic pleura; insets as indicated. $\mathbf{h}$ ROMIP 64362, close-up of posterior trunk exopods. i ROMIP 64363, close-up of anterior right cephalic region, dorsal view showing labrum and appendages; arrows point to overprint of gnathobases underneath cephalon. j, k ROMIP 64364 . j Close-up of distal portion of cephalic endopod, showing "platform" with setal brushes. k Close-up of terminal claw; arrows point to teeth on inner margin of claw. I USNM 144907, close-up of cephalic gnathobases; arrows point to dentate margins of opposing gnathobases. m ROMIP 64357, close-up on anterior left cephalic region, showing appendages; arrow points to anterior insertion of fourth cephalic endopod. $\mathbf{n}$ ROMIP 64359, close-up of cephalic appendages showing insertion of endopods on gnathobases; star marks attachment of fourth cephalic endopod on its gnathobase. $\mathbf{c}-\mathbf{f}, \mathbf{j}$ and $\mathbf{k}$ are SEM images; all other are stereomicroscope images of dry specimens under cross-polarized lighting. For abbreviations, see Methods. Scale bars: $(\mathbf{a}, \mathbf{g}, \mathbf{h}, \mathbf{i}, \mathbf{l}, \mathbf{n}), 1 \mathrm{~mm} ;(\mathbf{b}, \mathbf{m}), 0.5 \mathrm{~mm} ;(\mathbf{c}, \mathbf{d}, \mathbf{k}), 200 \mu \mathrm{m} ;(\mathbf{e}), 100 \mu \mathrm{m} ;(\mathbf{f}), 50 \mu \mathrm{m} ; \mathbf{( j )}, 500 \mu \mathrm{m}$

g, 2b, d); overall size of gnathobase also increasing posteriad, with anteriormost gnathobase inclusive of teeth roughly as wide as half the labrum $(2 \mathrm{~B}, \mathrm{D}, \mathrm{G}, \mathrm{L}, \mathrm{N})$ and posteriormost gnathobase with length of masticatory margin around a 1/4th of head length (Fig. 1c-e, g); gnathobases extensively overlapping (Figs. 1c, g, 2b, 1); masticatory margin with ca. 18 longer and shorter teeth arranged in two staggered rows, so that long and short teeth imbricate when opposing margins are closed; all teeth strongly sclerotized (Figs. 1c-e, g, 2d-f, n); both sets of teeth gradually decreasing in size proximalward; masticatory margin with convex latero-distal and latero- proximal margins; distalmost portion of masticatory margin pointing outward (Fig. 1e); from gnathobasic appendage 3 to 1 , teeth increasingly more slender, sharper and longer in relative size, so that the anteriormost gnathobase displays a morphology (short armature with long and slender teeth) substantially different from posteriormost (long armature with shorter, blunt, more robust teeth) (Fig. 2d, n).

Endopods seven-segmented, gradually increasing in size posteriorward, from $40 \%$ of head length to twice this size, with a distinctly larger increase between legs 3 and 4. (Figs. 1c, d, 2g-m); bent proximally and forming an 


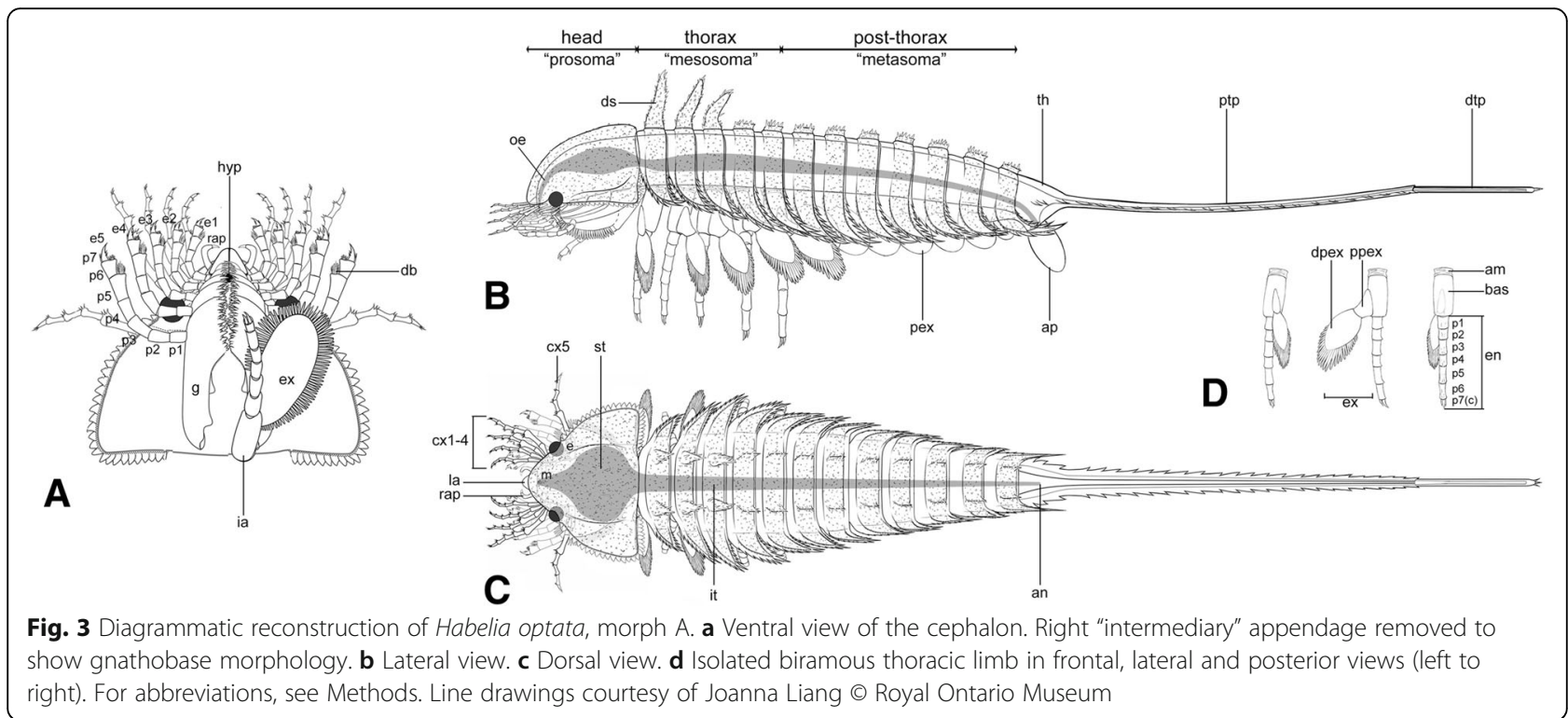

almost 90 degree angle between podomeres 2 and 4; podomere size formula is $[\mathrm{x} / \mathrm{x}+(1 / 5) \mathrm{x} / \mathrm{x}+(2 / 5) \mathrm{x} / \mathrm{x}$ $+(1 / 5) \mathrm{x} / \mathrm{x}+(2 / 5) \mathrm{x} / \mathrm{x} / \mathrm{x}$ (claw)] proximo-distally; terminal podomere a strong claw with two successive teeth on its ventral margin and adjoined by a pair of smaller, slender claws posteriorly (Fig. 2k); at least podomeres 2 and 3 bear well-developed enditic projections on their distalmost margins, forming platforms where insert bundles of more than 9 setae, of which the three central ones are more robust (Fig. $2 \mathrm{j}$ ); proximalmost podomere (1) of each endopod inserts on distal margin of corresponding gnathobase, close to the distal border of the masticatory margin (Fig. 2n).
Exopods are represented by five long and slender rami made of seven or more podomeres (Figs. 1, 2); each segmental junction bears three stiff setae (Fig. 2c); distalmost unit bears at least three setae; podomeres with diameter distinctly reduced proximal-ward and sub-concave margins (Fig. 2c); length of each subsequent podomere is ca. $20 \%$ greater than preceding podomere (Fig. 1a); all rami increasing gradually in size posteriorward, but first ramus distinctly shorter, only slightly longer than endopod of first gnathobasic appendage (Fig. 2i); attachment unclear, but does not appear to be on main branch of gnathobasic appendages; fifth ramus apart from the others in dorsal view and projecting more laterally close to the endopod of the

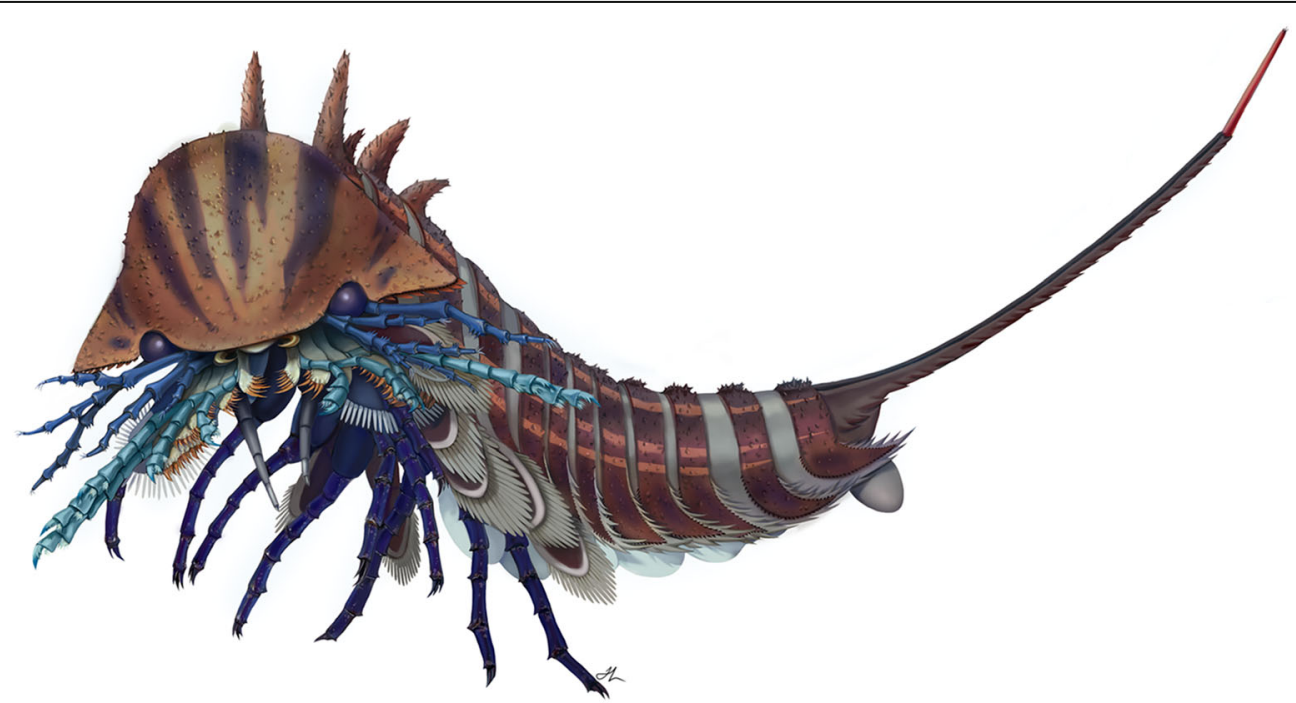

Fig. 4 Artistic reconstruction of Habelia optata. Courtesy of Joanna Liang @ Royal Ontario Museum 
fifth gnathobasic appendage, suggesting a different attachment (Fig. 2g and Additional file 3, Additional file 5, Additional file 7).

7th head appendage. One pair of biramous appendages located at junction between cephalon and trunk ("ia" in Figs. 1a, b, 2a, g, 3a); morphology similar to thoracic appendages, but reduced to ca. $2 / 3$ of length of first three trunk pairs; exopod more circular with finer and more numerous lamellae (Figs. 1b, 2a and Additional files).

Trunk ("opisthosoma"). Tergo-pleurae. 12-segmented, anatomically divided into anterior (five first segments, thorax or "mesosoma") and posterior (post-thorax or "metasoma") tagmata (Fig. 1); segments forming strongly bipartite tergo-pleurae, with an anterior portion ("doublure") mostly unadorned on its surface and a stronger, elevated posterior portion ("armature") covered in short blunt spines (similar to the surface of head shield) and produced into paired dorsal projections adorned with longer and sharper spines (Fig. 1); upper antero-lateral margin of armature fused with doublure, so that the discontinuity between doublure and armature is more pronounced on pleura and posterior side of segment (Additional files 3, 4); margin of doublure produced on its pleural circumference into sharp lanceolate spines growing more elongate distalward, with longest spines (ca. 2/3rd of segment length) on the posterior side of pleural distal extremity (Fig. 1b-g); margin of pleural part of armature adorned with minute spines; length of upper doublure less than half armature length in anterior segments but increasing posteriad to reach about identical length with armature; doublure width reducing on anterior side of pleura up to fusing with armature margin; on posterior side of pleura, margin of doublure closely parallel to margin of armature (Fig. 1b-g); anterior pleurae sub-horizontal, from segment 3 posteriorward gradually more parallel to body axis; pleura of first segment about 3/4th of cephalic pleura length, pleura of second segment subequal to cephalic pleura, pleura of third segment slightly longer than cephalic pleura, posterior pleurae gradually decreasing in size, except for pleura of last segment, forming an elongate blunt blade reaching back of telson base (Fig. 1b-g); margins of doublure and armature also increasingly curved posteriad.

Thoracic appendages. Biramous with well-developed endopods, present in trunk segments 1 to 5 (Fig. 1); appendages in segments 1-3 subequal, attachment to tip of endopod about $120 \%$ of head length; endopods of appendages 4 and 5 distinctly longer than $1-3$, with endopod 5 also slightly longer than 4 (Fig. 1 and Additional files 5, Additional file 6, Additional file 7).

Basipod broad and cylindrical, ca. 1/3rd of endopod length (Fig. $1 \mathrm{~b}$ and Additional file 6).
Endopod seven-segmented (six podomeres plus a claw); first (proximalmost) podomere quadrate, podomere size formula $[\mathrm{x} / \mathrm{x} / \mathrm{x}+(1 / 3) \mathrm{x} / \mathrm{x}+(1 / 4) \mathrm{x} / \mathrm{x}+(1 / 3) \mathrm{x}$ / $\mathrm{x}+(1 / 2) \mathrm{x} /(3 / 4) \mathrm{x}($ claw) $]$ proximo-distally (Fig. 1a-c, $\mathrm{g}$ and Additional files 4, Additional file 5, Additional file 6, Additional file 7); mesio-distal margins of podomeres forming thickened rims; terminal claw strong, length about half of podomere 6 , adjoined posteriorly by two smaller slender claws (Fig. 1a and Additional files 4, Additional file 5, Additional file 6, Additional file 7).

Exopods paddle-like, margins fringed with thin lamellar setae except on the most proximal left and right thirds; paddle connected to an attachment podomere inserted via an elongate hinge on the distal half of the basipod; exopod length about 2/3rd of endopod (Figs. 1b, 2a and Additional file 6).

Post-thoracic appendages. Broad, sub-spherical exopods slightly jutting out beneath pleurae from segment 6 to 12; exopod size decreasing gradually to segment 11 (Fig. 2h); exopod of last segment much smaller; no adornment visible; endopods presumably reduced or absent.

Tailpiece. Tailpiece a very long (subequal to slightly longer than head and trunk combined), bipartite, telson with spinose lateral margins (Fig. 1); first piece composed of a broad "base" (telson head) on the first 1/9th of its length and of an elongate, much thinner posterior rod-like extension with gentle dorsal concave curvature (Fig. 1a-g); on dorsal side of base, parallel carinae converging from positions of trunk protrusions on trunk tergites and running entire length of first telson piece (Fig. 1a-g); ventral side of base protruding, with sharp anterior slope, sub-straight margin pointing dorso-posteriorly and curved margin joining with more slender part of telson piece (Fig. 1a, b); an oblong cuticular structure, the anal pouch, is attached to sub-straight margin of some specimens, pointing posteroventrally (Fig. 1); length of anal pouch about $12 \%$ of length of first telson piece; lateral spines sharp, decreasing in size posteriad, all successive except for first two spines on base closer to one another than to following spine, itself followed by a gap before the next; second telson piece a straight articulating rod about $1 / 3 \mathrm{rd}$ of first telson piece length and ending in a set of three setae (Fig. 1f).

Remarks. We found Habelia brevicauda [38] to belong outside habeliidans, and the revision of this taxon is the object of a current study.

Habelia optata Walcott, 1912.

Synonymy

1912 Walcott, pp. 202-203, pl. 29, fig. 6

1920 Raymond, pp. 120-121

1920 Henricksen, pp. 16

1944 Størmer, p. 86

1959 Størmer, in Moore, p. 31, figs. 19, 3 (copy of

Walcott (1912)) 
1964 Simonetta, pp. 219-222, fig. 2, pl. xxxvi, unnumbered figures of USNM 57693, 139,209, 144,907-909

1975 Simonetta and Delle Cave, pp. 27, 32, pl. iii, fig 2a, b (reproduced from Simonetta (1964)), pl. xxi, figs. 1-3, figures of same specimens as Simonetta (1964)

1981 Whittington, pp. 343-346, fig. 61; figs. 62-66, plate 7; figs. 67-71, plate 8; figs. 72, 75-77; figs. 78-83, plate 9, fig. 130

Diagnosis. As per genus. Morph A (Figs. 1d-g, 3, 4 and Additional files 4A-D, 7E, F, J, K): First three anterior dorsal trunk projections long, with first longest (about $45 \%$ of head length), second slightly shorter than first and third slightly shorter than second; first projection pointing dorsally and other two pointing increasingly posteriad; antero-proximal portion of projections sub-straight, so that distal portions of projections 2 and 3 form an obtuse angle with that base; first pair of projections with antero-proximal base forming convex margin in lateral view; posterior dorsal projections convex dorsally, rounded anteriorly and pointed posteriorly. Morph B (Fig. 1a-c, h and Additional files 3, Additional file 5, Additional file 6, 7A-D, G-I): Five anterior-most pairs of dorsal spinose elevations forming rounded mounts decreasing in size posteriad and differentiated so that the pointed posterior end is moderately raised dorsalward: angle of posterior spinose projection with longitudinal plane of body ca. $70^{\circ}$ in ts $6,80^{\circ}$ in ts 5 (but with more rounded aspect) and $85^{\circ}$ in ts $4-1$; ornamental spines stronger, longer and more numerous on ts1-5; posterior dorsal projections convex dorsally, rounded anteriorly and pointed posteriorly.

Description. As per genus and diagnosis.

Remarks. Morphs A and B are clearly discriminated by the presence of anterior dorsal spines, with no indication of intermediaries, and no obvious relationship to overall size. This dichotomy does not overlap with the presence of "anal pouch," as the latter can be either present or absent in specimens with dorsal spines. It is worth noting that specimens with and without elongate trunk spines as well as specimens with or without anal pouch co-occur on the same stratigraphic levels within the Walcott quarry (Additional file 1). This supports the idea, on the basis of niche distribution, that these traits are conspecific, and that one of them likely characterizes sexual dimorphism. For this reason, we refrain from erecting distinct morphospecies based on these morphs, and both are considered for now to belong to H. optata.

\section{Phylogenetic results}

Our Bayesian analysis finds Habelia and Sanctacaris grouped in a clade at the base of Chelicerata (Fig. 5).
The Chelicerata clade is composed of paraphyletic "merostomes" (xiphosurans, eurypterids and chasmataspidids), from which emerges a monophyletic Arachnida. This topological arrangement is broadly consistent with the latest fossil-inclusive studies investigating chelicerate relationships [30, 56]. Contra [30], however, we find Offacolus and Dibasterium to lie as sister taxa to all other euchelicerates (as in $[56,57]$ ), in contiguity with habeliidans.

In the topology presented here, Chelicerata is equivalent to Euchelicerata because we removed Pycnogonida from the analysis. The phylogenetic position of pycnogonids has long been an issue $[47,51,58]$, and morphologically the presence of uniramous endopods (derived for euchelicerates) with a (possibly) four-segmented head tagma (plesiomorphic for arachnomorphs) are character states that are highly conflicting in this particular topology-especially with the inclusion of Habelia. Because of this, coding pycnogonids with a four-segmented head places them with Marrella at the base of the Artiopoda, whereas a seven-segmented coding affects the position of Offacolus and Dibasterium, bringing Limulus and Weinbergina as basalmost (due to their loss of exopods). We consider hereafter that pycnogonids still define Chelicerata as sister group to euchelicerates (i.e., branching immediately following habeliidans), but their exact phylogenetic placement will require further investigation.

In concordance with $[56,57]$, we retrieve Chasmataspis and Megalograptus as paraphyletic, but Limulus and Weinbergina as forming a clade. This could be due to our limited taxon sampling. The retrieval of cheiromorphs as part of a merostome clade by Garwood and Dunlop [30] may illustrate a problem of character polarization across higher nodes.

A notable difference with the previous analysis of this dataset under parsimony [9] is the retrieval of Arachnomorpha sensu Störmer [36], that is, the monophyletic group composed of Trilobitomorpha sensu lato (or Artiopoda sensu Hou and Bergström [4]) and Chelicerata. It has been recently shown that Arachnomorpha could result from a polarization bias overweighting the absence of characters in a dataset, for instance when coding inapplicable entries as additional states [27]. The fact that we retrieve here this clade using a Bayesian approach instead of parsimony, and after coding inapplicable entries as uncertainties, suggests that the grouping of trilobitomorphs with chelicerates excluding cheiromorphs (contra Arachnomorpha retrieved in refs. $[6,27])$ is a resilient configuration. Such resilience to methodological variations is further supported by the fact that these taxa have also been found to be monophyletic using implied weighting [8].

Additionally, the probabilistic approach does not support the monophyly of Hymenocarina and Megacheira. 


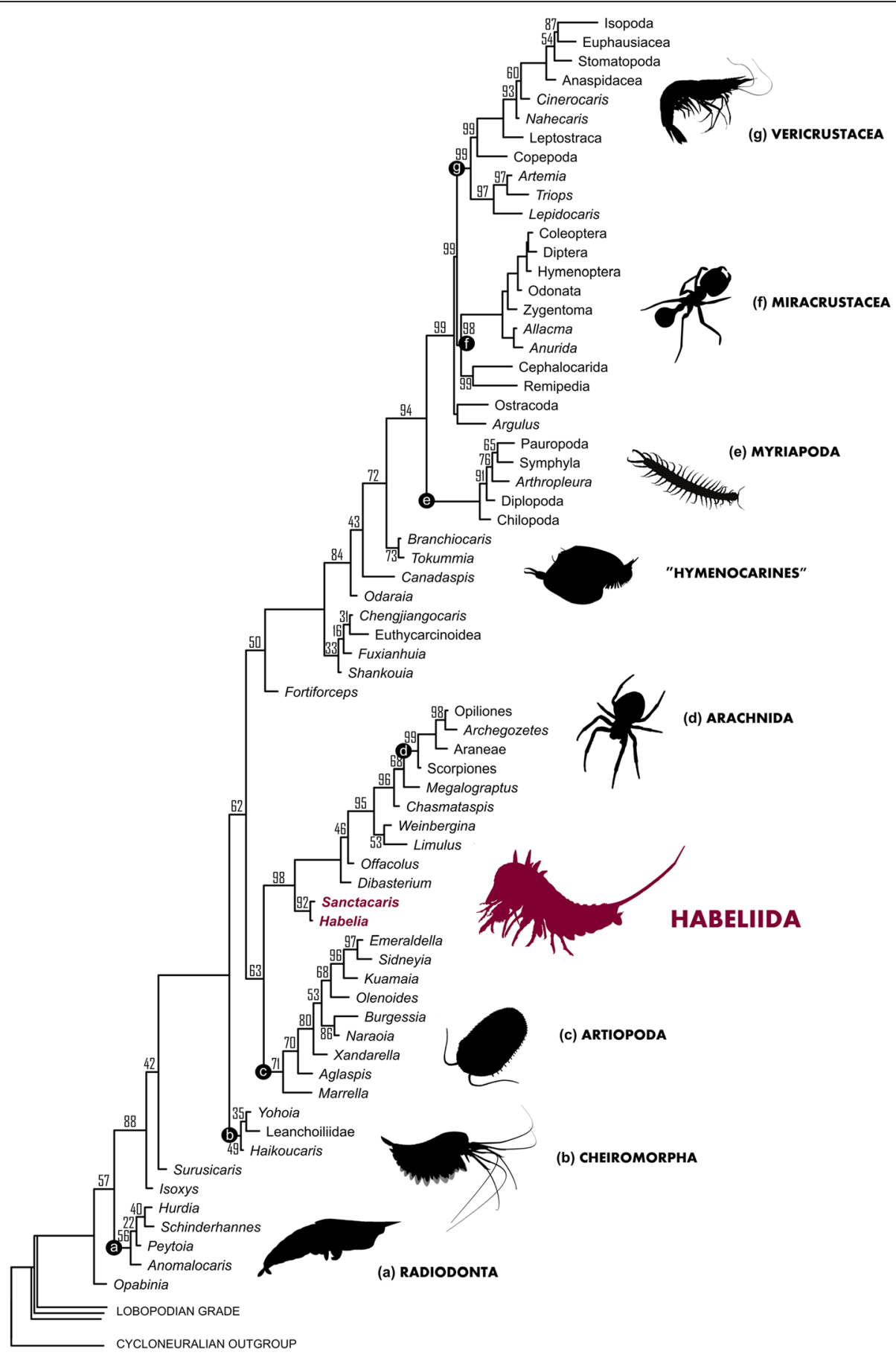

Fig. 5 Maximum clade credibility tree of a Bayesian analysis of arthropod relationships, using an Mkv model on a morphological matrix of 77 taxa and 215 characters. Habeliidans are in bold and red. Numbers next to nodes are posterior probabilities when $<100$

The critical uncertainties (e.g. presence of mandible) in the coding of large bivalved taxa related to protocaridids are likely responsible for the dissolution of Hymenocarina compared to the parsimony-based topology, since character state transformations are optimized differently under a Bayesian treatment. The redescription of these taxa in light of the new anatomical information provided by Tokummia and Branchiocaris [9], as well the detailed redescription of Waptia currently in progress, should help clarify the validity of Hymenocarina as a clade. The status of Megacheira is likewise dependent on the reevaluation of "multisegmented" forms such as Fortiforceps [4] with respect to the better-diagnosed Cheiromorpha [27]. 
The principal characters involved in the resolution of habeliidans are presented in Table 1 . The full development of endopods in the head tagma, presence of strong gnathobasic basipods and tripartite apoteles constitute the core characters supporting Arachnomorpha in our matrix. This result guided our revision of the arachnomorph diagnosis above. The positioning of habeliidans within "panchelicerates" is necessarily based on new or redefined characters constituting original apomorphies for this expanded chelicerate clade. We found that a seven-segmented cephalon (or prosoma) and the modification of posterior trunk appendages initially involving the complete reduction of the endopod are characters potentially diagnostic of the "panchelicerate" or totalgroup Chelicerata clade and plesiomorphic conditions of Chelicerata. The absence of chelicerae separates habeliidans from chelicerates, but the chelate condition is still uncertain in habeliidans and thus this exclusion should be regarded as provisional. It is also possible that the frontalmost endopods of habeliidans have a distal morphology intermediate between antennule and chelicera, which will require a revision of the definition of the chelicera itself. Euchelicerates remain securely established by the presence, as part of their ground pattern, of opisthosomal opercula.

\section{Discussion}

\section{Significance of morphology}

Several authors $[5,32,38]$ have recognized in habeliidans the peculiar bundled aspect of preservation of the anterior limbs. In Habelia, this configuration is associated with the presence, posterior to the frontal bundle, of unusually large gnathobases (Figs. 1c-e, g, 2b-n and Additional files 4, 7). These five gnathobases occupy most of the space under the cephalic shield, leaving no room for the insertion of other appendages. This condition, consistent with the anterior and horizontal position of the masticatory margins of those bases (Figs. 1c, g, 2d and Additional file 7), and the number and position of the "bundled" spinose limbs (Figs. 1a-d, 2b-n and Additional files 4, Additional file 5, Additional file 6, Additional file 7), must lead to the conclusion that the latter are endopods inserted distally, close to those toothed margins. In some cases, the attachment of the endopods on the gnathobasic basipods has been preserved (Fig. 2b, n). There is also evidence of a pair of appendages posterior to the gnathobases that seems to be inserted at the junction between the cephalon and trunk (Figs. 1a, b, 2a, g and Additional files 5, 6), and which would bear a large exopod adorned with very thin lamellae (Additional file 6). Such appendage is not dissimilar to what is known in the head of Sanctacaris (Additional files 1 and Additional file 9). The peculiar position of cephalic endopods in habeliidans is therefore genuine, and is due to the distal attachment of these endopods onto gnathobases increasingly large posteriad, occupying the seemingly unoccupied space under the cephalic shield.

In addition, there is a pair of reduced appendages anterior to the gnathobase-bearing limbs (Fig. 2i, M and Additional file 5). These frontalmost, reduced endopods occupy a topological position corresponding to the chelicerae, and are thus regarded as their likely precursors. At present, it is uncertain whether these appendages are chelate in Habelia, and they are not known in Sanctacaris (see Additional file 1). Our phylogeny (Fig. 5) does not allow conjecturing through the reconstruction of ancestral states either, as the placement of pycnogonids is uncertain (see Methods) and they are not included in our final analysis. From a functional point of view, the presence of reduced clawed appendages at the front may seem at odds with the association of the raptorial "bundle" of exopods and the gnathobases, much more efficient in grabbing and dissecting food items. Thus, for now, we refrain from formally assigning habeliidans to Chelicerata, eponymously defined by the presence of chelicerae (Table 1).

The "protochelicerae" at the front of Habelia's head flank a medial dome-shaped structure (Fig. 2g, i and Additional file 5). In dorsal view, this element shows no sign of suture, partial detachment or doublure, and its preservation lacks three-dimensionality. We do not think, therefore, that this is a sclerite, but rather a protrusion of the body. This soft protrusion is positioned just in front of the mouth, and thus conforms best to the labrum of chelicerates $[59,60]$. In ventral view, a more strongly sclerotized structure is preserved threedimensionally underneath the labrum, and likely has a similar shape. We tentatively homologize this ventral pre-oral sclerite with the hypostome of artiopodans and other pre-oral plates in extant groups. Such "hypostomo-labral complex" in habeliidans also calls for a comparison with a similar set of frontalmost features described in a number of hymenocarine mandibulates [9]. Since the frontal sclerite in protocaridids and Canadaspis is dorsal, instead of ventral, it probably does not correspond to the hypostome-like plate seen in Habelia. The feature shared by those taxa would therefore be the soft protrusion, or labrum per se, which may be bipartite in protocaridids [9]. The homology of the inter-ocular lobes in Canadaspis remains unclear, but it is worth noting that they occupy the same para-labral position as the "protochelicerae" of Habelia.

In Habelia, the frontalmost appendages, the five pairs of gnathobasic appendages and the thoracic-like biramous appendages inserted at the back of the head therefore lead to the formation of a cephalic tagma 
Table 1 Main diagnostic characters for clades inclusive of or related to habeliidans, and remarks on their significance. Potentially important characters with ambiguous optimization on the tree are italicized

\begin{tabular}{lll}
\hline Clade & Character & Remark \\
\hline Arachnomorpha & $\begin{array}{l}\text { All cephalic endopods fully developed } \\
\text { (char. 81) }\end{array}$ & $\begin{array}{l}\text { "Panchelicerates" and artiopodans are characterized by having well-developed } \\
\text { endopods-based on a heptopodomeran ground pattern [27]-in their head } \\
\text { tagmata. In mandibulates, at least one of these endopods is usually strongly } \\
\end{array}$ \\
& $\begin{array}{l}\text { modified; in leanchoiliids, the first post-frontal endopod is likely reduced [27, 67], } \\
\text { but the condition is not well known in other megacheirans. }\end{array}$
\end{tabular}

Third cephalic appendage gnathobasic (char. 107)

Presence of gnathobase(s) (char. 177)

Trunk endopods ending in set of three claws ("apotele") (char. 202)

Posteriormost trunk tergites fused into single plate (char. 212)

"Panchelicerata"

Ground pattern of a seven-segmented prosoma (chars. 32)

Trunk appendages with reduced or vestigial endopods (char. 183)

Labrum (char. 58)

Differentiation of the seventh prosomal appendage (char. 149)

Chelicerata

Chelicerae (char. 73)

Fused post-oral ganglia (char. 47)

Euchelicerata

Opercula on ventral surface of trunk (opisthosoma) (char. 151)

Post-frontal appendage with chelate or subchelate termination (char. 93)

Endosternum (char. 55)
We use here the term gnathobasic for a basipod with well-developed gnathal (usually dentate) edge on its proximal margin, without presence of a coxa. This is a possible ground pattern of Arachnomorpha.

By extension, the presence of a masticatory gnathobase on any body limb is another possible synapomorphy of arachnomorphs. This would not support the placement of Marrella [103] at the base of Artiopoda, but the proximal limb morphology in marellomorphs needs to be investigated in more detail.

Although the arrangement of the three terminal claws may vary, the tripartite apotele has already been presented as a potential synapomorphy of Arachnomorpha [104]. The claw complex seen in the thoracic endopods of habeliidans is consistent with this view.

Given our topology (Fig. 5), the thoracetron of xiphosurids and the pygidia of trilobites or other trilobitomorphs are not directly inherited from a common ancestor. The fact, however, that these structures are only found in arachnomorph arthropods suggests that the corresponding genetic pathways are shared and a possible case of parallelism.

We construe that in habeliidans, as in other xiphosurans $[62,66]$, the seventh appendage pair in the head is homologous to the chilaria. We also co-opt here the hypothesis that the "antennular" appendages of habeliidans are modified exopods of the head limbs, as previously interpreted in Sanctacaris [26, 32]

In this study, we propose that the absence of endopods on the posterior trunk appendages of habeliidans is an ancestral condition related to the reduction of biramous trunk appendages in chelicerates. In many cases, trunk appendages are still present among euchelicerates in vestigial form, such as spinnerets, ventral sacs, gonopods or genital acertabula [105].

The presence and homology of a "labrum" remains ambiguous in higher nodes of euarthropods, but remains diagnostic of "panchelicerate" (as shown herein) and mandibulate taxa. We propose here that the soft dorsal structure observed in habeliidans is equivalent to the soft elements identified underneath the frontal sclerite of protocaridids [9].

The value of this character depends on the semantic boundary assigned to "differentiated." We did not consider here that the seventh pair of appendages in habeliidans or Weinbergina was already differentiated compared to other trunk limbs. Ideally, this character will be refined using a more precise statement of differentiation, for the diagnosis of either Panchelicerata or Euchelicerata.

The chelate condition of the reduced frontalmost endopods of habeliidans is uncertain. However, contrarily to other characters evaluated here, the presence of chelicerae is the defining condition of Chelicerata, and therefore this clade could be enlarged in the future.

Whether this character can be coded in pycnogonids is not clear [106]. A single post-oral nerve mass has been interpreted in a leanchoiliid from China [29], but it appears to us that the central nervous system cannot be clearly isolated from other tissues in their specimen (such as cephalic shield and appendages), and thus the origin of this condition remains uncertain.

The presence of ventral opisthosomal plates called opercula has been shown to be a likely apomorphy of euchelicerates [65], which is supported herein. No evidence of elements possibly homologous to opercula have been found in habeliidans, although we did not have access to a clear ventral view of the trunk.

Given the basal phylogenetic position of Offacolus, Dibasterium and xiphosurids, a chelate or subchelate pedipalp (or walking leg in xiphosurans) may be considered a groundplan character of Euchelicerata. However, this condition is clearly highly convergent in euchelicerates overall, and whether it represents broad parallelism bears on the resolution and morphology of synziphosurines at the base of euchelicerates.

The euchelicerate endosternum is of course difficult to document in fossils, which hampers an assessment of its origin. 
encompassing seven pairs of appendages. Although most chelicerates are diagnosed by the possession of a sixsegmented prosoma [28], the chilaria of xiphosurids and the possible implementation of a seventh pair in Weinbergina had raised the question of a seven-segmented prosoma possibly representing the chelicerate ground pattern [61]. This hypothesis was strengthened by the publication of Offacolus, a possible stem euchelicerate also sporting a seventh (and differentiated) appendage under its head shield [62]. The opisthosomal origin of the chilaria, demonstrated both embryologically [63] and morphologically [64], however, suggested that the integration of that first opisthosomal limb into the prosoma could be a derived character present in all "xiphosuran" taxa.

The anatomy of habeliidans shows that this condition is present outside of the "xiphosuran" body plan and our topology (Fig. 5) suggests that a cephalon with seven segments (i.e. eight somites) resolves as a plesiomorphic condition of Chelicerata. This means that the studies documenting the opisthosomal affinity of the seventh prosomal appendage $[63,64]$ were in fact providing atavistic evidence for a transformation that occurred in the ancestor of all "panchelicerates," and possibly reflecting a morphological variability present at the origin of arachnomorphs. In this evolutionary context, Habelia allows us to link the xiphosurid chilaria [65] to a fullyformed, opisthosoma-like biramous limb. In arachnids, this somite is usually considered the first of the opisthosoma, but shows a variety of morphological differentiations, such as a constriction associated with a reduced tergite-as is the case in Araneae [28]. As we discuss below, the biramous limb corresponding to this somite in habeliidans stems itself from a typical cheiromorph limb.

The "antenna-like rami" of Sanctacaris, as Briggs and Collins [32] originally called them, have been recently compared to the stenopodous exopods of the "xiphosurans" Offacolus and Dibasterium [26]. These frontal appendages in Sanctacaris and Habelia are in fact quite distinct morphologically from the exopods of Offacolus and Dibasterium, with long and slender podomeres, giving them indeed a more "antennular" aspect. Similar to at least Dibasterium (but also likely Offacolus [66]), however, these rami in Habelia are preserved separately from the endopod "bundle" in non dorso-ventrally-preserved specimens, suggesting that they do not attach to the limb basis like regular exopods. In Dibasterium, the basipod itself was reported absent [66]. Notwithstanding the phylogenetic placement of pycnogonids and its impact on the polarization of characters on the tree (see (b) Phylogenetic results), this condition may constitute a strong argument that Offacolus and Dibasterium are indeed basal taxa [56, 57], close to habeliidans.
Specimens of Habelia preserve the first four of these long anterior rami also bundled together, and sometimes even apparently attached at their base, except for the fifth one preserved more posteriorly and pointing laterally (Figs. 1c, 2g, and Additional files 3, 5, 7). If they indeed represent dissociated exopods, their possible partial fusion at the base would be secondarily acquired, rather than demonstrating any relationship with "great appendages" or any other appendage pair belonging to its own somite. The anatomy and morphology of habeliidans thus challenge the direct morphological continuity between cheiromorph "great appendages" and chelicerae as proposed by some authors [24, 25] in favour of an intermediate, reduced state that may not have been chelate.

There are, however, shared characters between megacheirans and habeliidans, which not only have an important impact on phylogenetic relationships but also, consequently, on the alignment of the various euarthropod body plans. One of our main findings is that Habelia bears thoracic appendages of typical cheiromorph morphology [24, 25, 27, 67, 68]: long, subcylindrical, non-gnathobasic basipods, to which are attached a twosegmented, paddle-like exopod fringed with oblanceolate lamellae and a seven-segmented endopod with limited proximo-distal podomere differentiation (Fig. 1a-c, g, 2a and Additional files 4, Additional file 5, Additional file 6, Additional file 7). This condition in Habelia (and, potentially, in habeliidans) conflicts with the existence of a stem lineage to chelicerates composed of artiopodans (as in ref. [26]), because such a hypothesis would imply a major reversal of gnathobasic limbs with differentiated exopods through all trunk segments. Hence the opisthosomal limbs of chelicerates might have never been gnathobasic, and some in-group apomorphies might well be plesiomorphies instead. This is the case, for example, for the "13 opisthosomal segments" character used by Lamsdell [69] to define the clade "Dekatriata." Counting the "release" of the seventh pair of cephalic appendages, this character was already defining habeliidans, while 12 trunk segments were present in a cheiromorph such as Yawunik [27].

The direct implication for the alignment of the "panchelicerate" and cheiromorph trunks is that a large discrepancy between head tagma arises. Given that the plesiomorphic head tagma consists of four segments (as in isoxyids [44] and megacheirans [27]), the two or three added pairs must have been incorporated to the cephalon from existing trunk segments. However, as mentioned, the number of trunk segments in this part of the arthropod tree is rather well conserved in adults, with documented variations of only one or two segments (Fig. 6). This implies the insertion of up to three additional somites within the 


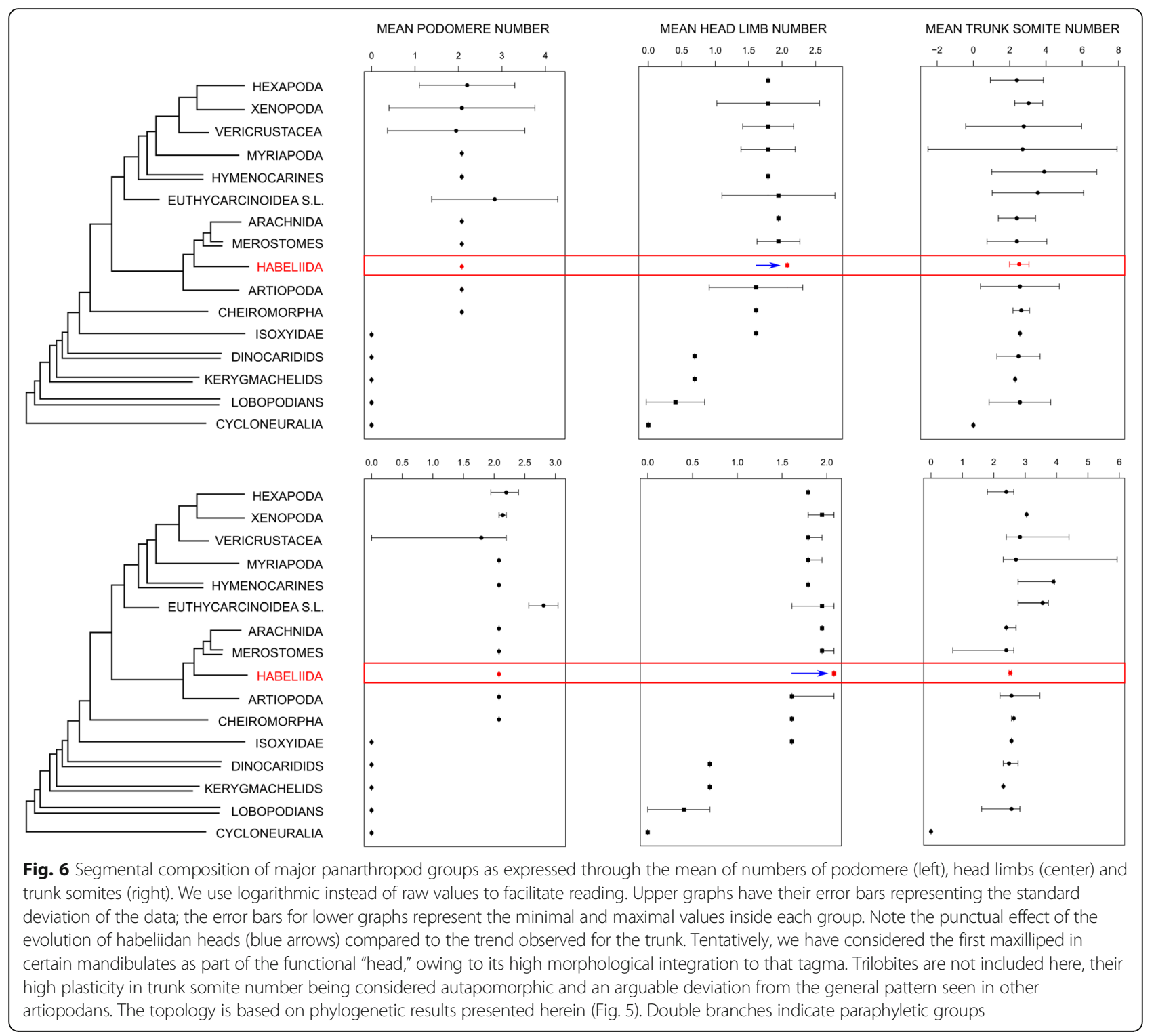

head either de novo or from the trunk with a subsequent adjustment of the total number of trunk somites. In both cases, such an anatomical transition could represent an event of punctuated equilibrium [70], as already reported for instance in certain centipedes with single speciation events involving the addition of numerous somites [71].

Xenopodans-represented by Sidneyia and Emeraldella-have long been suggested as possible links to chelicerates from trilobitomorph ancestors $[26,36]$. However, the head composition of Sidneyia remains mostly unknown [72], while Emeraldella, described as having a ground-pattern type of head tagma with four appendage pairs [73], is more likely to have five cephalic pairs, including antennules, and a trunk of 12 segments. Perhaps more compelling is Xanderalla spectaculum Hou et al.
[74] from the Chengjiang biota, with a 12-segmented trunk and a set of six post-antennular cephalic limbs, the last of which is close to the articulation with the first trunk segment [4]. Interestingly, the cephalon of Xandarella retains moulting sutures isolating an anteriormost section made of the antennules plus three appendage pairs [4], typical, by contrast, of the arthropod ground pattern $[44,75,76]$.

By retrieving Artiopoda and "Panchelicerata" as two separate clades, our current cladogram (Figs. 5, 6) thus favours morphological variability and possible parallelism over gradual acquisition of a chelicerate-like prosoma. This topological configuration is notably supported by the plesiomorphic condition of habeliidan trunk appendages. In this context, the common arachnomorph ancestor probably had a head tagma composed 
of five or more somites, but had acquired developmental plasticity in the formation of the anterior tagma. Given the constraint in trunk somite number observed in closely related taxa (but released in trilobites [77]), such plasticity possibly involved the addition of de novo somites directly to the head. Pycnogonids, which also include variations in appendage number among taxa [28], could be representative of such selective release of developmental canalization in basal arachnomorphs.

Considering the morphological differences between the frontalmost appendages of megacheirans, artiopodans and habeliidans, and assuming homology between these, the frontalmost appendages of the arachnomorph ancestor is difficult to reconstruct. However, we can hypothesize an intermediate morphology in the form of a short, antennular, monobranch "great appendage"; a condition which could have given rise to both the long antennules of most artiopodans and the reduced "protocheliceral" appendages of habeliidans. Fossil euarthropods such as Fortiforceps [4], Jianfengia [78] and Kiisortoqia [79] bear frontalmost appendages that could be representative of such intermediate condition.

The rear tagma of Habelia ("metasoma") bears pairs of well-developed rounded exopods, with no obvious substructure-only poorly-defined traces on posterior appendages that we can, at best, interpret as folds. Hence the specimens provide no evidence of the presence of lamellate gills characteristic of chelicerates, or of an equivalent of opisthosomal opercula [65]. There is also no trace of accompanying endopods, however, suggesting they may be reduced/vestigial, which so far has been also a diagnostic trait of Chelicerata. It appears therefore that the reduction of posterior endopods came first in the evolution of "panchelicerates," leaving the metasoma possibly specialized for respiratory functions, although the surface of gaseous exchanges cannot be determined yet with Habelia (it may have been the surface of the exopods themselves). We assume that these exopods were later modified to become the gill-bearing opercula of euchelicerates.

A peculiar aspect of the morphology of Habelia is the rich adornment of the body-not seen in Sanctacaris. The only equivalents for such cuticular differentiations amongst Cambrian arthropods are the prosopon of trilobites, especially in their tubercular forms [80]. This could be seen as evidence reinforcing the monophyly of Arachnomorpha. Another characteristic that to some extent can be observed in trilobites is the strong differentiation of individual trunk segments between anterior and posterior parts. Such a phenotype is reminiscent of parasegmental patterns. Parasegmental development, which in extant taxa is known to be regulated by the pair-rule and patterning genes fushi-tarazu, even-skipped, engrailed and wingless at segmental boundaries [81], represent fundamental subdivisions of the post-cephalic development in euarthropods, prior to the consolidation of the somites as the final metameric units. In some cases, parasegmental boundaries express morphological differentiation in early embryos, such as in the opisthosoma of the model spider Cupiennius salei [81]. Given its posterior affinity and its strong impact on development, it is possibly the same mechanism that is at the origin of the tergo-pleural subdivisions in the trunk of Habelia. This would mean that part of the downstream regulation replacing parasegmental patterns would be inactivated in this taxon. If so, it would be reasonable to think that other aspects of the development might have been altered (or "relaxed"), especially with respect to the head tagma.

\section{Palaeoecological implications}

Although the masticatory margins of Habelia's cephalic gnathobases bear similarities to those of other arachnomorphs, especially those of Sidneyia's trunk limbs [72, 82], their relative size, posteriad increase of absolute size, shape and orientation (i.e., sub-parallel to the frontal plane of the head) make them unique amongst all known arthropods.

In fact, the best functional analogs for dentate masticatory margins opposing parallel to the antero-posterior axis would be the mandible and other masticatory apparatuses present in the more differentiated heads of mandibulates (Fig. 7). In malacostracans and terrestrial mandibulates in particular, mandible, maxillule, maxilla and sometimes maxillipeds' proximal podomeres also often form a succession of strong crushing sclerites often aided by modified endopods (palps) to constitute very efficient chewing devices capable of dissecting hard chitinous, sometimes mineralized cuticles or shells, in the vicinity of the mouth opening $[83,84]$. This implies that at least some stem chelicerates could have occupied a typically benthic malacostracan niche in Cambrian marine ecosystems.

As a fundamental distinction, gnathal structures in mandibulates are derived from coxae, themselves being additional basal podomeres originating from the development of basipod endites [9, 85-89], while artiopodan and chelicerate gnathobases are transformations of the basipod itself. Furthermore, the successive appendages are morphologically near identical in habeliidans (except for variation in overall size as well as tooth length), while they are most of the time individually differentiated in mandibulates, as a means of performing slightly different but complementary functions. This simpler plesiomorphic, "serial" head configuration has likely provided habeliidans with a proportionally much stronger raw crushing power-analogous to an insect, myriapod or malacostracan being equipped with four additional 


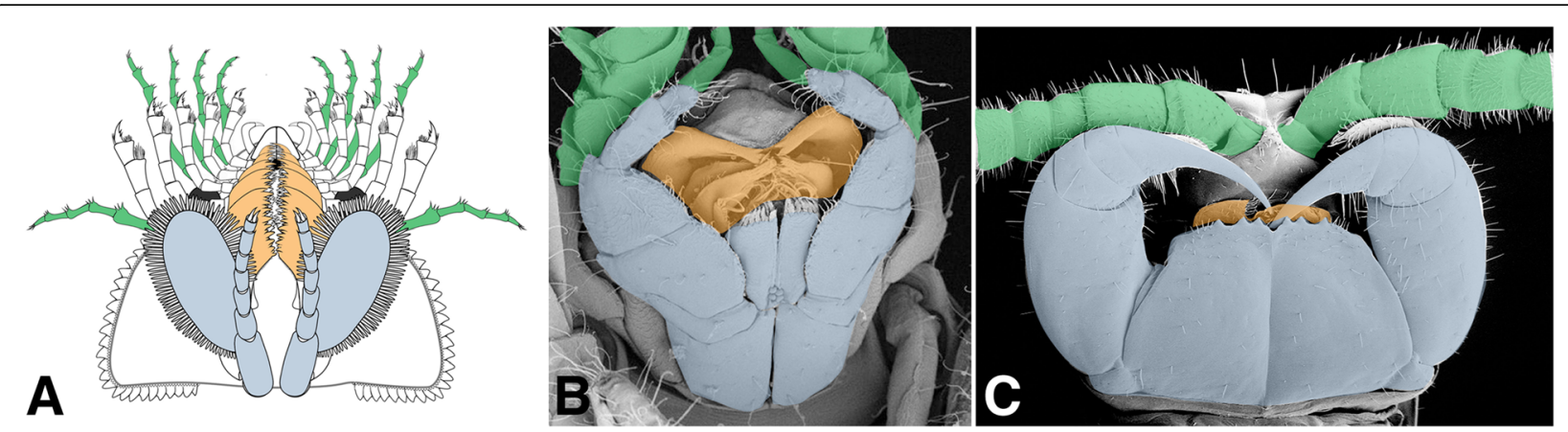

Fig. 7 Convergences in head anatomy and morphology between Habelia (a) and selected mandibulates, in this case laniropsis sp. (Malacostraca: Isopoda; b; (c) Buz Wilson, Australian Museum) and Henicops washpoolensis (Myriapoda: Chilopoda; c; image provided by G. Edgecombe). Colours highlight the morpho-functional correspondence between sensory appendages (exopods in Habelia vs. antennae in mandibulates; green), masticatory appendages (gnathobases in Habelia vs. mandibles and maxillae in mandibulates; orange) and complimentary appendages aiding in food manipulation (seventh head appendage in Habelia vs. maxillipeds in mandibulates; blue). Note that masticatory appendages in Henicops are hidden by the large coxosternites of the maxillipeds

mandibles, albeit of different sizes. It is not known if these appendages were able to work in concert, creating a single movement of closure, or in series, as is the general condition for arthropod appendages; however, even if habeliid gnathobases were closing with a slight offset, the resulting movement still represented strength-wise the action of several consecutive mandibles.

Adding to the resemblance with mandibulates is the fact that the cephalic exopods were differentiated into antennule-like appendages, presenting a long and slender morphology, bearing stiff setae at the podomere junctions (Fig. 2c), and projecting at the front of the animal. Although external resemblance needs not always imply similar functions, this very peculiar form of exopods, in association with spinose endopods interpreted as having a raptorial role, leads to think that they were most likely used complementarily to sense the environment and prey items. We therefore regard them as sensory or tactile apparatuses (Figs. 3, 4, 6 and Additional file 8).

Whether this spectacular specialization was an autapomorphy of habeliidans or a plesiomorphic condition of chelicerates is not known, but similarities in the arrangement of exopodial branches in Offacolus and Dibasterium suggest that the first chelicerates may indeed have co-opted exopods as sensory/tactile features as a way to compensate for the lack of dedicated antennular appendage, locked by newly integrated developmental pathways. The later radiation of the group formed predatory niches discarding sensory/tactile apparatuses anteriorly in favour of median eyes, but a tactile function was to reappear in the arachnid pedipalps, and sensorial abilities through the modification of walking legs (endopods) in whip scorpions, whip spiders and many harvestmen.

The comparative picture is completed by the additional pair of appendages integrated to the head tagma-the "intermediary" appendage of Habelia, morphologically similar to those of the "mesosoma," and the first maxilliped of mandibulates such as centipedes or isopods (Fig. 7). While it is argued here that this pair of appendages in habeliidans is plesiomorphic for Chelicerata, the integration of the first maxilliped into the head appears on the contrary highly convergent across mandibulates. Functionally, integrated maxillipeds represent an additional pair of limbs aiding in food manipulation, and this is also what we infer for the seventh cephalic pair in Habelia (and likely Sanctacaris). Given the difference in morphology between the latter relatively long appendages and the anterior enditic endopods, such a posterior pair would have helped sensing and maintaining the food in place during the action of the gnathobases (which is similar to the role of labial palps in many insects).

The size differentiation between cephalic gnathobases, differential length of teeth and development of spinose endopods as well as sensory/tactile rami point to a combination of active predatory, prey-grasping lifestyle with a type of food processing concentrated in the mouth area. The abundance of trilobites and the rise of shelly metazoans in Cambrian seas have called for postulating an array of durophagous niches [90-93], of which the most prominent actors were likely artiopodans themselves [94-96] with their well-developed gnathobases. Some might have been more-or-less selective predators [95], others more scavengers [96], but these body plans have mostly stood-albeit controversially [93, 97]-in contrast to other possible large hard-shell feeders, anomalocaridids [98], which were swimming and equipped with grasping appendages. Although small in absolute size, the cephalic gnathobases of habeliidans seem to have specifically evolved as adaptations to durophagous niches. This is notably supported by the 
presence of trilobite fragments within the gut of the habeliidan Wisangocaris barbarahardyae [35].

\section{Conclusions}

Habeliidans contribute to build a richer and more dynamic view of the benthic Cambrian faunas, in which small active predators also adapted to a diet based on hard and mineralized shells (Additional file 8). Arguably, strongly sclerotized mouthparts brought advantages other than the processing of thicker cuticles and shells (such as the possibility of developing new functions on other limb bases) and were not necessarily associated with such feeding habits (the small mandibles of Tokummia [9] and relatively delicate, specialized claws would rather point to soft-bodied prey items). Nonetheless, our general phylogenetic results and the new evidence provided by the study of Habelia indicate that the adaptation to durophagous niches may have broadly triggered the radiation of Artiopoda, Chelicerata and Mandibulata.

In its nature and extent, such morphological convergence between an early chelicerate and mandibulates has no other equivalent, and in that pertains the question of morphological variability and disparity among stem lineages. How much habeliidans would impact the early arthropod morphospace remains to be tested, but they represent an arguable departure from all related body plans, while sharing an ancestor with chelicerates and some morpho-functionality with mandibulates. In light of the evidence discussed above, namely sudden changes in head anatomy (from four- to seven-segmented) and appendage morphology (drastic modification of the basipod and "detachment" of exopods), as well as clues for possible upstream alterations in the development (parasegmental-like morphology of tergo-pleurae), Habelia seems to stem from a remarkable morphological variability in the common ancestor of chelicerates-as may pycnogonids and their challenging anatomies. Findings for very high evolutionary rates at the base of extant clades are consistent with this hypothesis [19]. This could support the idea that the Cambrian was marked by profound changes in gene regulatory networks [99], although the resulting macroevolutionary patterns may be more complex than an overall lower disparity for extant taxa [2, 100, 101].

The current palaeontological evidence suggests that habeliidans may not have survived beyond the Cambrian. If, as the convergence in the sclerotization of head appendages seems to suggest, they were competing with early mandibulates for small durophagous benthic prey items, they might not have been able to adapt to the transformation of those niches during the Ordovician, or may have been outcompeted by the ability of mandibulates to evolve various morphological specializations among head appendages. Owing to the view that poor developmental canalization could have been detrimental to the long-term fitness of stem taxa [102], the structural lability that habeliidans had inherited from the arachnomorph ancestor may have ultimately affected their likelihood of survival.

\section{Additional files}

Additional file 1: Additional text including list of material, modifications of the phylogenetic matrix and comments on Sanctacaris uncata Briggs and Collins. (PDF 113 kb)

Additional file 2: Dataset file containing morphological data and code for phylogenetic analysis in MrBayes (Fig. 5), and segment data used for the variability graphs (Fig. 6). (TXT $44 \mathrm{~kb}$ )

Additional file 3: Habelia optata Walcott. (A-F) USNM 144908. (A) Full specimen, preserved latero-dorsally. Insets as indicated. (B) Close-up of spine-shaped pleura on posteriormost segment. (C) Close-up of thorax (mesosoma) and cephalon (prosoma). Insets as indicated. (D) Close-up of trunk pleurae. Arrowheads point to anterior margin of cuticular armature. (E) Close-up of head shield ornamentation, photographed in direct light. (F) Close-up of ornamental spines along the head shield margin. All pictures taken in cross-polarized light, unless otherwise indicated. See Methods for abbreviations. Scale bars: $5 \mathrm{~mm}(A) ; 1 \mathrm{~mm}(C, D, E) ; 0.5 \mathrm{~mm}$ (B, F). (JPEG $1911 \mathrm{~kb}$ )

Additional file 4: Habelia optata Walcott. (A-D) USNM 272169. (A) Full specimen, preserved in latero-dorsal aspect. Insets as indicated. (B) Closeup of distal portion of thoracic endopod, showing claw (podomere 1) and podomeres 2 and 3. (C) Close-up of distalmost portion of cephalic endopods, showing terminal claw and podomere 2 with well-developed endite. (D) View of entire thoracic endopod. (E-F) USNM 305091. (E) Full specimen, preserved in dorsal aspect. Arrowheads point to taphonomic breakage in telson. (F) View of entire thoracic endopod. All images using cross-polarizing light. Scale bars: $1 \mathrm{~mm}$ (A, D-F); $0.5 \mathrm{~mm}$ (B, C). (JPEG $2042 \mathrm{~kb}$ )

Additional file 5: Habelia optata Walcott. (A) ROMIP 64363, specimen preserved in latero-dorsal aspect; see also Fig. 2i. (B-D) ROMIP 64357; see also Figs. 1a, 2m. (B) Counterpart of (C), close-up of thorax (mesosoma) and cephalon (prosoma). (C) Full specimen before preparation, preserved in latero-dorsal aspect. Inset is (D). (D) Close-up of anterior region of prosoma, showing anterior reduced appendage and endpods 1-3, after preparation. (E-G) ROMIP 64364 (F, G counterpart of E); see also Fig. 2g-k. (E) Full specimen, preserved in dorsal aspect. (F) Close-up of prosoma. Inset is (G). (G) Close-up of labrum, hypostome and distal portion of cephalic endopods. All pictures taken in cross-polarized light. See Methods for abbreviations. Scale bars: 10 mm (E); 5 mm (A-C, F); 1 mm (D, G). (JPEG 1654 kb)

Additional file 6: Habelia optata Walcott. (A-D) USNM 139209; see also Figs. 1b, h, 2a. (A) Full specimen, preserved in latero-dorsal aspect. (B) Focus on tergite ornamentation using low angle plain light. (C) Close-up of cephalic and thoracic appendages. Note cheiromorph morphology of biramous mesosomal appendages. Inset is (D). (D) Close-up of eye. Arrowheads point to margin of ocular notch. (E-G) ROMIP 64368. (E) Full specimen, preserved in latero-dorsal aspect. Insets as indicated. (F) Close-up of posterior region. (G) Close-up of area beneath cephalic shield, showing exopod of intermediary appendage. Arrowhead points to margin of cephalic pleura. All pictures taken in cross-polarized light, unless otherwise indicated. See Methods for abbreviations. Scale bars: (A, B, E), 4 mm; (C), $2 \mathrm{~mm}$; (D), $0.5 \mathrm{~mm}$; (G, F), 1 mm. (JPEG $1989 \mathrm{~kb}$ )

Additional file 7: Habelia optata Walcott. (A, B) ROMIP 64370. (A) Full specimen preserved in dorsal aspect. Inset is (B). (B) Close-up of intestinal tract and wide stomach located within the cephalon. (C, D) ROMIP 64358, counterpart of Fig. 1c; see also Fig. 2d. (C) Full specimen, preserved in latero-dorsal aspect; composite image of both part and counterpart. Inset is (D). (D) Close-up of cephalic and thoracic appendages. Arrowheads point to overlapping bases of antennular exopod rami. We construe that the fifth spinose cephalic endopods was taphonomically displaced, as is suggested by the retracted position of the posteriormost gnathobases. ( $E$, F) ROMIP 64359; see also Figs. 1d, e, 2n. (E) Twisted specimen preserved 
in latero-dorsal (trunk) and latero-ventral (head) aspect. Close-up of head and trunk. (F) Same as E, direct light. Arrowheads point to paired, serially repeated phosphatized structures of uncertain nature. Their dislocation from the intestine and atypical shape cast doubt on an interpretation as midgut glands. (G-I) ROMIP 64352; see also Fig. 2h. (G) Full specimen, preserved in latero-ventral aspect. Insets as indicated. (H) Close-up of metasomal exopods. (I) Close-up of prosoma. Left cephalic endopods are preserved stacked on top of each other next to their corresponding gnathobases. "Exopod" rami are preserved apart from the main appendage structure; their point of attachment is unclear. (J, K) ROMIP 64379, H. optata, possibly morph A, from the Tulip Beds (Mount Stephen). (J) Full specimen, preserved in latero-dorsal aspect. (K) Counterpart of J. All pictures taken in cross-polarized light, unless otherwise indicated. See Methods for abbreviations. Scale bars: $5 \mathrm{~mm}(\mathrm{~A}-\mathrm{C}, \mathrm{G}, \mathrm{I}, \mathrm{J}) ; 2 \mathrm{~mm}(\mathrm{E}, \mathrm{F})$; $1 \mathrm{~mm}(\mathrm{D}, \mathrm{H}, \mathrm{K})$. (JPEG $1949 \mathrm{~kb})$

Additional file 8: Artistic illustration of Habelia optata. Courtesy of Joanna Liang $\odot$ Royal Ontario Museum. (TIFF $9740 \mathrm{~kb}$ )

Additional file 9: Sanctacaris uncata Briggs and Collins, Holotype ROMIP 43502. Part (A) and partial counterpart (B) both discovered in 1983 . lower weathered portion of the counterpart never before published was discovered in 2007. (A) Full specimen, preserved in dorsal aspect. Insets as indicated. (B) Full specimen, counterpart. Inset is (C). (C) Close-up of anterior region of prosoma. Inset is (I). (D) Specimen photographed in direct light after coating in ammonium chloride sublimate. Arrowheads point to small dorsal carinae on trunk tergites. (E) Close-up of anterior trunk appendages on right side of body, possibly the corresponding exopods of (F) with setae not preserved. (F) Close-up of exopod of first and second trunk appendages. (G) Close-up of cephalic appendages posterior to raptorial "bundle," showing paddle-like exopod interpreted as belonging to the intermediary appendage, and small appendage with distal setal brush of unclear identity. (H) Close-up on first cephalic endopod showing five well-developed endites on inner margins of podomeres, and possibly an additional one proximally. (I) Close-up of frontalmost region, showing morphology of cephalic endopods 1-3. Endites indicated by asterisks. Ventral face of labrum revealing bipartite frontal morphology (demarcation pointed by arrow) with paired reflective spots. (J) Close-up of cephalic endopod claw. Arrowhead point at tooth on inner margin of main claw; arrow points at secondary claw behind main claw. All pictures taken in cross-polarized light, unless otherwise indicated. Additional abbreviations: ed., endite(s); edn, endite $n$; iex, exopod of intermediary appendage; texn, trunk exopod $n$. See Methods for remaining abbreviations. Scale bars: 10 mm (A, B); 5 mm (C, D); 1 mm (E-J). (JPEG $1526 \mathrm{~kb}$ )

\section{Acknowledgements}

We thank Mark Florence and Doug Erwin for providing access to Walcott's collections of the Smithsonian Institution at the National Museum of Natural History. We are likewise grateful to Joanna Liang, who produced the artwork depicting Habelia as part of her Master's thesis at the University of Toronto (Biomedical Communication). Gregory Edgecombe kindly provided imagery of Henicops washpoolensis, and the Australian Museum gave us cordial permission to use their photograph of laniropsis. The comments of three anonymous reviewers helped substantially improve the original manuscript. We also thank Peter Fenton and Maryam Akrami for collection assistance at the Royal Ontario Museum. This is Royal Ontario Museum Burgess Shale project number 74 .

\section{Funding}

CA's research was supported by fellowships from the University of Toronto (Dept. of Ecology and Evolution) and J-BC's Natural Sciences and Engineering Research Council Discovery Grant (\#341944). These funding bodies took no part in the design of the study or collection, analysis, and interpretation of data, or in writing the manuscript.

\section{Availability of data and materials}

All data generated or analysed during this study are included in the supplementary information files of this published article.

\section{Authors' contributions}

CA wrote the initial draft of the manuscript and produced the phylogenetic analyses. J-BC prepared and took photographs of the specimens. Both authors contributed to the interpretation of fossils and the final version of the manuscript and figures. Both authors read and approved the final manuscript.

Ethics approval and consent to participate

Not applicable

\section{Consent for publication}

Not applicable

\section{Competing interests}

The authors declare that they have no competing interests.

\section{Publisher's Note}

Springer Nature remains neutral with regard to jurisdictional claims in published maps and institutional affiliations.

\section{Author details}

${ }^{1}$ Department of Ecology and Evolutionary Biology, University of Toronto, Toronto, ON M5S3B2, Canada. ${ }^{2}$ Department of Natural History (Palaeobiology Section), Royal Ontario Museum, Toronto, ON M5S2C6, Canada. ${ }^{3}$ Department of Earth Sciences, University of Toronto, Toronto, ON M5S3B1, Canada. ${ }^{4}$ Present address: State Key Laboratory of Palaeobiology and Stratigraphy, Nanjing Institute of Geology and Palaeontology, Chinese Academy of Sciences, Nanjing 210008, China.

Received: 17 July 2017 Accepted: 21 November 2017

Published online: 21 December 2017

\section{References}

1. Whittington HB. Early arthropods, their appendages and relationships. In: House MR, editor. The Origin of Major Invertebrate Groups. London and New York: Academic Press; 1979. p. 253-68.

2. Gould SJ. Wonderful life. The Burgess Shale and the nature of history. New York: Norton; 1989.

3. Briggs DEG, Fortey RA. The early radiation and relationships of the major arthropod groups. Science. 1989;246:241-3.

4. Hou XG, Bergström J. Arthropods of the lower Cambrian Chengjiang fauna, southwest China. Fossils Strata. 1997:45:1-116.

5. Budd GE. A palaeontological solution to the arthropod head problem. Nature. 2002;417(6886):271-5.

6. Cotton TJ, Braddy SJ. The phylogeny of arachnomorph arthropods and the origin of the Chelicerata. Trans R Soc Edinb Earth Sci. 2004;94:169-93.

7. Daley AC, Budd GE, Caron JB, Edgecombe GD, Collins D. The Burgess Shale anomalocaridid Hurdia and its significance for early euarthropod evolution. Science. 2009:323(5921):1597-600.

8. Legg DA, Sutton MD, Edgecombe GD. Arthropod fossil data increase congruence of morphological and molecular phylogenies. Nat Commun. 2013;4

9. Aria C, Caron J-B. Burgess Shale fossils illustrate the origin of the mandibulate body plan. Nature. 2017;545:89-92.

10. Wills MA, Briggs DEG, Fortey RA, Wilkinson M, PHA S. An arthropod phylogeny based on fossil and recent taxa. In: Edgecombe GD, editor. Arthropod fossils and phylogeny. New York: Columbia University Press; 1997. p. 347.

11. Budd GE. The Cambrian fossil record and the origin of the phyla. Integr Comp Biol. 2003:43(1):157-65.

12. Lamsdell JC, Stein M, Selden PA. Kodymirus and the case for convergence of raptorial appendages in Cambrian arthropods. Naturwissenschaften. 2013; 100(9):811-25.

13. Madsen O, Scally M, Douady CJ, Kao DJ, DeBry RW, Adkins R, Amrine HM, Stanhope MJ, de Jong WW, Springer MS. Parallel adaptive radiations in two major clades of placental mammals. Nature. 2001; 409(6820):610-4.

14. Muschick M, Indermaur A, Salzburger W. Convergent evolution within an adaptive radiation of cichlid fishes. Curr Biol. 2012;22(24):2362-8.

15. Mahler DL, Ingram T, Revell LJ, Losos JB. Exceptional convergence on the macroevolutionary landscape in island lizard radiations. Science. 2013; 341(6143):292-5. 
16. Maruyama M, Parker J. Deep-time convergence in rove beetle symbionts of army ants. Curr Biol. 2017;27(6):920-6.

17. Vinther J, Stein M, Longrich NR, Harper DAT. A suspension-feeding anomalocarid from the early Cambrian. Nature. 2014;507(7493):496-9.

18. Caron J-B, Aria C. Cambrian suspension-feeding lobopodians and the early radiation of panarthropods. BMC Evol Biol. 2017:17

19. Lee MSY, Soubrier J, Edgecombe GD. Rates of phenotypic and genomic evolution during the Cambrian explosion. Curr Biol. 2013;23(19):1889-95.

20. Briggs DEG, Fortey RA, Wills MA. Morphological disparity in the Cambrian. Science. 1992;256(5064):1670-3.

21. Wills MA. Cambrian and recent disparity: the picture from priapulids. Paleobiology. 1998;24(2):177-99.

22. Gould SJ. The disparity of the Burgess Shale arthropod fauna and the limits of cladistic analysis: why we must strive to quantify morphospace. Paleobiology. 1991;17(4):411-23.

23. Hughes M, Gerber S, Wills MA. Clades reach highest morphological disparity early in their evolution. Proc Natl Acad Sci U S A. 2013;110(34):13875-9.

24. Chen JY, Waloszek D, Maas A. A new 'great-appendage' arthropod from the lower Cambrian of China and homology of chelicerate chelicerae and raptorial antero-ventral appendages. Lethaia. 2004;37(1):3-20.

25. Haug JT, Waloszek D, Maas A, Liu Y, Haug C. Functional morphology, ontogeny and evolution of mantis shrimp-like predators in the Cambrian. Palaeontology. 2012;55:369-99.

26. Legg DA. Sanctacaris uncata: the oldest chelicerate (Arthropoda). Naturwissenschaften. 2014;101(12):1065-73.

27. Aria C, Caron J-B, Gaines R. A large new leanchoiliid from the Burgess Shale and the influence of inapplicable states on stem arthropod phylogeny. Palaeontology. 2015;58(4):629-60.

28. Dunlop JA, Lamsdell JC. Segmentation and tagmosis in Chelicerata. Arthropod Struct Dev. 2016:46(3):395-418.

29. Tanaka G, Hou X, Ma X, Edgecombe GD, Strausfeld NJ. Chelicerate neural ground pattern in a Cambrian great appendage arthropod. Nature. 2013; 502(7471):364-7.

30. Garwood RJ, Dunlop J. Three-dimensional reconstruction and the phylogeny of extinct chelicerate orders. Peerj. 2014;2

31. Liu Y, Haug JT, Haug C, Briggs DEG, Hou X. A 520 million-year-old chelicerate larva. Nat Commun. 2014;5

32. Briggs DEG, Collins D. A Middle Cambrian chelicerate from Mount Stephen, British Columbia. Palaeontology. 1988;31:779-98.

33. Legg DA, Pates S. A restudy of Utahcaris orion (Euarthropoda) from the Spence Shale (middle Cambrian, Utah, USA). Geol Mag. 2017;154(1):181-6.

34. Lerosey-Aubril R, Skabelund J. Messorocaris, a new sanctacaridid-like arthropod from the middle Cambrian Wheeler Formation (Utah, USA). Geol Mag. 2017;Online publication:1-6.

35. Jago JB, Garcia-Bellido DC, Gehling JG. An early Cambrian chelicerate from the Emu Bay Shale, South Australia. Palaeontology. 2016;59(4):549-62.

36. Størmer L: On the relationships and phylogeny of the fossil and recent Arachnomorpha. A comparative study on Arachnida, Xiphosura, Eurypterida, Trilobita, and other fossil Arthropoda. Skrifter utgitt av Det Norske VidenskapsAkademi i Oslo Matematisk-Naturvidenskapelig klasse 1944;5:1-158.

37. Walcott C. Cambrian geology and paleontology II. Middle Cambrian Branchiopoda, Malacostraca, Trilobita and Merostomata. Smithsonian Miscellaneous Collections. 1912;57(6):145-228.

38. Simonetta AM: Osservazioni sugli arthropodi non trilobiti della "Burgess Shale" (Cambriano medio). Monitore Zoologico Italiano 1964, 72(3-4: III Contributo: I Generi Molaria, Habelia, Emeraldella, Parahabelia (Nov.), Emeraldoides (Nov.):215-231.

39. Simonetta AM, Delle Cave L. The cambrian non trilobite arthropods from the Burgess Shale of British Columbia. A study of their comparative morphology taxinomy and evolutionary significance. Palaeontographia Italica. 1975;69(39):1-37.

40. Raymond PE. The appendages, anatomy and relationships of trilobites. Memoirs of the Connecticut Academy of Arts and Sciences. 1920;7:1-169.

41. Henriksen KL: Critical notes upon some Cambrian arthropods described by Charles D. Walcott. Videnskabelige Meddelelser fra Dansk Naturhistorisk Forening: Khobenhavn. 1928:86:1-20.

42. Fedotov D. On the relations between the Crustacea, Trilobita, Merostomata and Arachnida. Bulletin de l'Académie des Sciences de Russie. 1924:383-408.

43. Whittington HB: Rare arthropods from the Burgess Shale, Middle Cambrian, British Columbia. Philosophical Transactions of the Royal Society of London Series B, Biological Sciences 1981;292(B 1060):329-357.
44. Aria C, Caron J-B. Cephalic and limb anatomy of a new isoxyid from the Burgess Shale and the role of "stem bivalved arthropods" in the disparity of the frontalmost appendage. PLoS One. 2015;10(6)

45. Ronquist F, Teslenko M, van der Mark P, Ayres DL, Darling A, Hohna S, Larget B, Liu L, Suchard MA, Huelsenbeck JP. MrBayes 3.2: efficient Bayesian phylogenetic inference and model choice across a large model space. Syst Biol. 2012;61(3):539-42

46. Lewis PO. A likelihood approach to estimating phylogeny from discrete morphological character data. Syst Biol. 2001;50(6):913-25.

47. Rota-Stabelli O, Campbell L, Brinkmann H, Edgecombe GD, Longhorn SJ, Peterson KJ, Pisani D, Philippe H, Telford MJ. A congruent solution to arthropod phylogeny: phylogenomics, microRNAs and morphology support monophyletic Mandibulata. Proc R Soc Lond. 2011;278(1703):298-306.

48. Borner J, Rehm P, Schill RO, Ebersberger I, Burmester T. A transcriptome approach to ecdysozoan phylogeny. Mol Phylogenet Evol. 2014;80:79-87.

49. O'Reilly JE, Puttick MN, Parry L, Tanner AR, Tarver JE, Fleming J, Pisani D, Donoghue PCJ. Bayesian methods outperform parsimony but at the expense of precision in the estimation of phylogeny from discrete morphological data. Biol Lett. 2016;12(4)

50. Wright AM, Hillis DM. Bayesian analysis using a simple likelihood model outperforms parsimony for estimation of phylogeny from discrete morphological data. PLoS One. 2014;9(10)

51. Regier JC, Shultz JW, Zwick A, Hussey A, Ball B, Wetzer R, Martin JW, Cunningham CW. Arthropod relationships revealed by phylogenomic analysis of nuclear protein-coding sequences. Nature. 2010;463(7284): 1079-98.

52. Prevosti FJ, Chemisquy MA. The impact of missing data on real morphological phylogenies: influence of the number and distribution of missing entries. Cladistics. 2010;26(3):326-39.

53. Wiens JJ. Missing data, incomplete taxa, and phylogenetic accuracy. Syst Biol. 2003;52(4):528-38.

54. Raymond PE. Notes on invertebrate fossils, with descriptions of new species. Bull Mus Comp Zool Harv Univ. 1931;55(6):165-213.

55. Zhang $X L$, Zhao YL, Yang RD, Shu D. The Burgess Shale arthropod Mollisonia ( $M$. sinica new species); new occurrence from the middle Cambrian Kaili fauna of Southwest China. J Paleontol. 2002;76:1106-8.

56. Lamsdell JC, DEG B, Liu HP, Witzke BJ, RM MK. A new Ordovician arthropod from the Winneshiek Lagerstätte of lowa (USA) reveals the ground plan of eurypterids and chasmataspidids. Science of Nature. 2015;102:9-10.

57. Selden PA, Lamsdell JC, Qi L. An unusual euchelicerate linking horseshoe crabs and eurypterids, from the lower Devonian (Lochkovian) of Yunnan, China. Zool Scr. 2015;44(6):645-52.

58. Maxmen A, Browne WE, Martindale MQ, Giribet G. Neuroanatomy of sea spiders implies an appendicular origin of the protocerebral segment. Nature. 2005:437(7062):1144-8.

59. Dunlop JA. The epistomo-labral plate and lateral lips in solifuges, pseudoscorpions and mites. Ekologia-Bratislava. 2000;19:67-78.

60. Shultz JW. Morphology of the prosomal endoskeleton of Scorpiones (Arachnida) and a new hypothesis for the evolution of cuticular cephalic endoskeletons in arthropods. Arthropod Struct Dev. 2007;36(1):77-102.

61. Moore RA, Briggs DEG, Bartels C. A new specimen of Weinbergina opitzi (Chelicerata: Xiphosura) from the lower Devonian Hunsrück slate, Germany. Paläontol Z. 2005;79(3):399-408.

62. Sutton MD, Briggs DEG, Siveter DJ, Orr PJ: The arthropod Offacolus kingi (Chelicerata) from the Silurian of Herefordshire, England: computer based morphological reconstructions and phylogenetic affinities. Proc R Soc Lond. 2002; 269(1497):1195-1203.

63. Scholl G. Beiträge zu Embryonalenentwicklung von Limulus polyphemus L. (Chelicerata, Xiphosura). Zoomorphologie. 1977;86:99-154.

64. Shultz JW. Gross muscular anatomy of Limulus polyphemus (Xiphosura, Chelicerata) and its bearing on evolution in the Arachnida. J Arachnol. 2001; 29(3):283-303.

65. Dunlop JA: The origins of tetrapulmonate book lungs and their significance for chelicerate phylogeny. In: Proceedings of the 17th European Colloquium of Arachnology: 1997; Edinburgh.

66. Briggs DEG, Siveter DJ, Sutton MD, Garwood RJ, Legg D. Silurian horseshoe crab illuminates the evolution of arthropod limbs. Proc Natl Acad Sci U S A. 2012;109(39):15702-5.

67. Haug JT, Briggs DEG, Haug C. Morphology and function in the Cambrian Burgess Shale megacheiran arthropod Leanchoilia superlata and the application of a descriptive matrix. BMC Evol Biol. 2012;12:162. 
68. Bruton DL, Whittington HB. Emeraldella and Leanchoilia, two arthropods from the Burgess Shale, middle Cambrian, British Columbia. Philos Trans Royal Soc London, Series B. 1983;300:553-82.

69. Lamsdell JC. Revised systematics of Palaeozoic horseshoe crabs' and the myth of monophyletic Xiphosura. Zool J Linnean Soc. 2013;167(1):1-27.

70. Gould SJ, Eldredge N. Punctuated equilibria: the tempo and mode of evolution reconsidered. Paleobiology. 1977;3:115-51.

71. Minelli A, Chagas A, Edgecombe GD. Saltational evolution of trunk segment number in centipedes. Evol Dev. 2009;11(3):318-22.

72. Stein M. Cephalic and appendage morphology of the Cambrian arthropod Sidneyia inexpectans Walcott, 1911. Zoologisher Anzeiger. 2013;253(2):164-78.

73. Stein M, Selden PA. A restudy of the Burgess Shale (Cambrian) arthropod Emeraldella brocki and reassessment of its affinities. J Syst Palaeontol. 2012; 10(2):361-83.

74. Hou XG, Bergström J. The arthropods of the lower Cambrian Chengjiang fauna, with relationships and evolutionary significance. In: Simonetta AM, Conway Morris S, editors. The early evolution of Metazoa and the significance of problematic taxa. Camerino: Cambridge University press; 1991. p. 179-87.

75. Cisne JL. Anatomy of Triarthrus and the relationship of the Trilobita. Fossils Strata. 1975:4:45-63.

76. Walossek D: On the Cambrian diversity of Crustacea. In: Crustaceans and the Biodiversity Crisis, Proceedings of the Fourth International Crustacean Congress, Amsterdam, The Netherlands. Edited by Schram FR, von Vaupel Klein JC, vol. 1. Leiden: Brill Academic Publishers.; 1999: 3-27.

77. Webster M, Cambrian A. Peak in morphological variation within trilobite species. Science. 2007;317(5837):499-502.

78. Hou X. Two new arthropods from the lower Cambrian, Chengjiang, eastern Yunnan. Acta Palaeontol Sin. 1987;26(3):250-6

79. Stein M. A new arthropod from the early Cambrian of North Greenland, with a 'great appendage'-like antennula. Zool J Linnean Soc. 2010;158(3): 477-500.

80. Whittington HB. Fossils illustrated - trilobites. Woodbridge: Boydell Press; 1992.

81. Damen WGM. Parasegmental organization of the spider embryo implies that the parasegment is an evolutionary conserved entity in arthropod embryogenesis. Development. 2002;129(5):1239-50.

82. Bruton DL. The arthropod Sidneyia inexpectans, middle Cambrian, Burgess Shale, British Columbia. Philos Trans R Soc Lond, Series B. 1981;295:619-53.

83. Schram FR: Crustacea: Oxford university press; 1986.

84. Harmer SF, Shipley AE (eds.): Peripatus, Myriapods and insects, part I. London: Macmillan; 1901.

85. Popadic A, Panganiban G, Rusch D, Shear WA, Kaufman TC. Molecular evidence for the gnathobasic derivation of arthropod mandibles and for the appendicular origin of the labrum and other structures. Dev Genes Evol. 1998;208(3):142-50.

86. Walossek D, Müller KJ: Cambrian 'Orsten'-type arthropods and the phylogeny of Crustacea. In: Arthropod relationships. Edited by Fortey RR, Thomas R. London: Chapman \& Hall; 1998;139-153.

87. Boxshall GA. The evolution of arthropod limbs. Biol Rev. 2004;79(2):253-300.

88. Coulcher JF, Telford MJ. Comparative gene expression supports the origin of the incisor and molar process from a single endite in the mandible of the red flour beetle Tribolium castaneum. EvoDevo. 2013;4

89. Coulcher JF, Edgecombe GD, Telford MJ. Molecular developmental evidence for a subcoxal origin of pleurites in insects and identity of the subcoxa in the gnathal appendages. Sci Rep. 2015;5

90. Conway Morris S, Bengton S. Cambrian predators: Possible evidence from boreholes. J. Paleontol. 1994:68:1-23.

91. Skovsted CB, Brock GA, Lindstrom A, Peel JS, Paterson JR, Fuller MK. Early Cambrian record of failed durophagy and shell repair in an epibenthic mollusc. Biol Lett. 2007;3(3):314-7.

92. Vannier J. Gut contents as direct indicators for trophic relationships in the Cambrian marine ecosystem. PLoS One. 2012;7(12):e52200.

93. Bicknell RDC, Paterson JR: Reappraising the early evidence of durophagy and drilling predation in the fossil record: implications for escalation and the Cambrian explosion. Biol Rev. 2017; early view:1-31.

94. Bergström J, Hou XG, Halenius U. Gut contents and feeding in the Cambrian arthropod Naraoia. GFF. 2007;129(2):71-6.

95. Zhu MY, Vannier J, Van Iten H, Zhao YL. Direct evidence for predation on trilobites in the Cambrian. Proc R Soc Lond Ser B. 2004;271(SUPPL. 5):277-80.
96. Zacai A, Vannier J, Lerosey-Aubril R. Reconstructing the diet of a 505million-year-old arthropod: Sidneyia inexpectans from the Burgess Shale fauna. Arthropod Struct Dev. 2016;45(2):200-20.

97. Daley A, Bergström J. The oral cone of Anomalocaris is not a classic 'peytoia'. Naturwissenschaften. 2012;99(6):501-4.

98. Nedin C. Anomalocaris predation on nonmineralized and mineralized trilobites. Geology. 1999;27(11):987-90.

99. Erwin DH, Laflamme M, Tweedt SM, Sperling EA, Pisani D, Peterson KJ. The Cambrian conundrum: early divergence and later ecological success in the early history of animals. Science. 2011;334(6059):1091-7.

100. Foote M. Morphological disparity in Ordovician-Devonian crinoids and the early saturation of morphological space. Paleobiology. 1994;20(3):320-44.

101. Hopkins MJ, Smith AB. Dynamic evolutionary change in post-Paleozoic echinoids and the importance of scale when interpreting changes in rates of evolution. Proc Natl Acad Sci U S A. 2015;112(12):3758-63.

102. Peterson KJ, Dietrich MR, McPeek MA. MicroRNAs and metazoan macroevolution: insights into canalization, complexity, and the Cambrian explosion. BioEssays. 2009;31(7):736-47.

103. García-Bellido DC, Collins DH. A new study of Marrella splendens (Arthropoda, Marrellomorpha) from the middle Cambrian Burgess Shale, British Columbia, Canada. Can J Earth Sci. 2006;43:721-42.

104. Dunlop JA. Character states and evolution of the chelicerate claws. European Arachnology. 2000;2002:345-54

105. Sharma PP. Chelicerates and the conquest of land: a view of arachnid origins through an evo-devo spyglass. Integr Comp Biol. 2017;57(3):510-22.

106. Edgecombe GD, Wilson GDF, Colgan DJ, Gray MR, Cassis G. Arthropod cladistics: combined analysis of histone $\mathrm{H} 3$ and $\mathrm{U} 2$ snRNA sequences and morphology. Cladistics. 2000;16(2):155-203.

\section{Submit your next manuscript to BioMed Central and we will help you at every step:}

- We accept pre-submission inquiries

- Our selector tool helps you to find the most relevant journal

- We provide round the clock customer support

- Convenient online submission

- Thorough peer review

- Inclusion in PubMed and all major indexing services

- Maximum visibility for your research

Submit your manuscript at www.biomedcentral.com/submit

) Biomed Central 